\title{
MARKET POLARIZATION AND THE PHILLIPS CURVE
}

2021

\section{BANCODEESPAÑA \\ Eurosistema}

\section{Documentos de Trabajo}

N. ${ }^{\circ} 2106$

Javier Andrés, Óscar Arce and Pablo Burriel 
MARKET POLARIZATION AND THE PHILLIPS CURVE ${ }^{(*)}$

Javier Andrés ${ }^{(*)}$

UNIVERSIDAD DE VALENCIA

Óscar Arce ${ }^{(* * x)}$ and Pablo Burriel ${ }^{(* * *)}$

BANCO DE ESPAÑA

${ }^{(*)}$ We thank Fabio Ghironi and Pau Roldan for comments and discussions. Javier Andrés acknowledges the financial support by the Spanish Ministry of Economy and Competitiveness (grant ECO2017-84632-R) and Generalitat Valenciana (grant GVPROMETEO/2020/083).

(*) Universidad de Valencia. E-mail: javier.andres@uv.es.

$\left.{ }^{\star \star \star}\right)$ Banco de España. E-mail: o.arce@bde.es.

$\left.{ }^{\star \star \star \star *}\right)$ Banco de España. E-mail: pburrie!@bde.es.

Documentos de Trabajo. N. ${ }^{\circ} 2106$

2021 
The Working Paper Series seeks to disseminate original research in economics and finance. All papers have been anonymously refereed. By publishing these papers, the Banco de España aims to contribute to economic analysis and, in particular, to knowledge of the Spanish economy and its international environment.

The opinions and analyses in the Working Paper Series are the responsibility of the authors and, therefore, do not necessarily coincide with those of the Banco de España or the Eurosystem.

The Banco de España disseminates its main reports and most of its publications via the Internet at the following website: http://www.bde.es.

Reproduction for educational and non-commercial purposes is permitted provided that the source is acknowledged.

C BANCO DE ESPAÑA, Madrid, 2021

ISSN: 1579-8666 (on line) 


\section{Abstract}

The Phillips curve has flattened out over the last decades. We develop a model that rationalizes this phenomenon as a result of the observed increase in polarization in many industries, a process along which a few top firms gain an increasing share of their industry market. In the model, firms compete à la Bertrand and there is exit and endogenous market entry, as well as optimal up and downgrading of technology. Firms with larger market shares find optimal to dampen the response of their price changes, thus cushioning the shocks to their marginal costs through endogenous countercyclical markups. Thus, regardless of its causes (technology, competition, barriers to entry, etc.), the recent increase in polarization in many industries emerges in the model as the key factor in explaining the muted responses of inflation to movements in the output gap witnessed recently.

Keywords: firm heterogeneity, Bertrand competition, Phillips curve, market share.

JEL classification: E31, E52, L1. 


\section{Resumen}

La pendiente de la curva de Phillips se ha reducido en las últimas décadas. En este documento se desarrolla un modelo que racionaliza este fenómeno a partir del aumento del grado de polarización observado en muchas industrias, que ha supuesto que un reducido número de grandes empresas de cada industria acumula en una cuota de mercado cada vez mayor. En el modelo, las empresas compiten a la Bertrand y deciden óptimamente la entrada y la salida del mercado, así como su nivel de tecnología. Para las empresas con una mayor cuota de mercado resulta ventajoso moderar los cambios en sus precios y que sus márgenes absorban parte de las variaciones en sus costes marginales, de forma que se acentúa su comportamiento contracíclico. De acuerdo con el modelo, el aumento de la polarización observado en muchas industrias en las últimas décadas, independientemente de sus causas (tecnología, grado de competencia, barreras de entrada, etc.), es un factor clave para explicar la respuesta tan moderada de la inflación ante los cambios advertidos en los últimos años en la brecha de producción.

Palabras clave: heterogeneidad empresarial, competencia a la Bertrand, curva de Phillips, cuota de mercado.

Códigos JEL: E31, E52, L1. 


\section{Introduction}

The pattern of inflation rates across most advanced economies in recent years defies the traditional explanations based on the Phillips curve relation between inflation and the output gap. The fears of deflation after the global financial crisis (GFC) were successfully tackled by the bold response undertaken by the major central banks. However, in spite of the implementation of an unprecedented set of non-conventional monetary policy measures, including massive quantitative easing programs, banking liquidity schemes, forward guidance on the future interest rate path and, in some jurisdictions, negative short-term interest rates, inflation and inflation expectations in most advanced economies remained chronically subdued even before the Covid-19 crisis.

Closely related to the anaemic path of consumption prices in many advanced economies over the last decade is the lack of inflation response to cyclical conditions evidenced after the GFC. Moreover, some argue that the weakening of the prices response to changes in resource utilization comes from afar and potentially well before the GFC (see e.g. IMF, 2013, Blanchard, 2016, and Powell, 2018). Prominent among the potential explanations for the muted reaction of prices to cyclical conditions are the weakening of labor power, the rise of globalization and international trade, and the impact of positive supply shocks caused by new technologies.

For one thing, it seems true that labor bargaining power has fallen due to rising firms' concentration and market power and the resurgence of monopsony power in some specific segments of the labour market (see e.g. Krueger, 2018, and Stansbury and Summers, 2020). But, as the IMF (2019b) has recently shown, labor costs have risen faster than productivity in many European countries, despite which inflation remains rather muted. Regarding productivity, it is worth noticing that the fast rise observed during the nineties, in particular in the U.S., has not been sustained and, if anything, the coincidence of a poor performance of productivity and the development of new technologies is seen by many nowadays as puzzling (Aghion, Bergeaud, Boppart, Klenow and Huiyu, 2019). As for globalization, it is not a recent process but one that dates back to the 1970's and 1980's when international trade liberalization gathered momentum. Moreover, according to several metrics, if anything, globalization may have lost some traction over the last years, especially since the GFC (World Bank, 2020).

All the previous factors may have had an effect on inflation and other relevant economic variables, but they certainly do not exhaust the list of possible causes behind the diminishing effect of cyclical fluctuations on prices. A related strand of literature is placing increasing attention on some ongoing significant changes in the industrial structure in advanced economies. These changes include, among others, the rise in market shares in many industries, industrial polarization along different 
dimensions (e.g. firm size, productivity, etc.), the rise in markups, intensification of competition spurred by technology and the decline of the labor share. Yet, so far little consensus can be found about the likely effect of these factors on the inflation rate or, more precisely, on the link between inflation and the economic slack (Van Reenen, 2018).

The case for market concentration over the last decades has been firmly established on empirical grounds. Covarrubias, Gutiérrez and Philippon (2019), who offer evidence on the increase in market concentration in most industries in the U.S. since the 1980s, distinguish among different potential causes behind this phenomenon. They refer to good concentration as the one driven by increases in the elasticity of substitution and enhanced technological efficiency and productivity by the leading firms in each industry, whereas a form of bad concentration would emerge as a result of higher entry costs and other barriers to competition.

Some commentators have emphasized the role of new technological giants in shaping the way economies respond to shocks, the archetypal case being the disinflationary impact of Amazon (see e.g. Gros, 2017, and Cohen, 2017). This is in stark contrast with the long held view in mainstream macroeconomics according to which market concentration has been considered a source of inflationary pressure, frequently modelled as a shock to the markup in the New Keynesian Phillips curve. According to this predominant view, market concentration and markups are positively related, both reflecting the level of a firm's market power. As the argument goes, rising markups, as documented in recent decades, would lead firms to set increasingly higher prices as an optimal response to a given positive shock to current and expected marginal costs. Consequently higher market power would imply higher inflation in this type of models, which is inconsistent with the muted response of inflation observed in recent decades (IMF, 2019a).

In this paper we set up a model that sheds light on the connection between the rise in market concentration (in terms of market shares and polarization of firms' size and productivity) and the flattening of the Phillips curve. Contrary to the previous standard view, in our model, the rise in market shares is neither inflationary nor deflationary per se, but it reduces the slope of the Phillips curve. Key to this result is the fact that markups, which are endogenous in our setting, depend positively on the firm's market share. When a firm faces a positive shock to its marginal cost it raises prices, which in turn undermines its market share and hence its desired markup, thus dampening the inflationary effect of the shock. The bigger the firm's market share, the stronger is this effect. Hence, in an economy featuring highly polarized industrial structures, with a few large and many small competitors in each industry, much in line with the aforementioned recent evidence, the response of inflation to shocks becomes more muted than it would be in a similar economy with a more balanced distribution of firms. 
The mechanism hinges critically on the joint effect of two core features of the industrial structure of the economy regarding the presence of heterogeneous firms in terms of their technology and pricing policy. As in Etro and Rossi (2015), Andrés and Burriel (2018), and, more recently, Wang and Werning (2020), we assume that there is Bertrand competition so that firms take into account the expected reaction of other competitors when setting their prices. ${ }^{1}$ Furthermore, unlike in Andrés and Burriel (2018) where the number of firms is fixed and heterogeneity in technology is exogenously established, here we assume endogenous firm entry as well as an optimal choice of the class of technology in which each firm operates out a pool of available options that differ in their TFP level. These features are critical to endogenize firms' market shares, so that the share of more technologically advanced firms may be sizeable, even in the presence of a large number of competitors.

Our New Keynesian model, augmented with Bertrand price competition and endogenous heterogeneity on firm technology delivers a mechanism that rationalizes why firms with larger market shares respond less to shocks to their marginal cost. While strategic price interactions barely affect the markup of smallish firms, they do condition the desired markup of large firms in a material manner. This moderates the response of prices set by the later to shocks, which in turn (upon aggregation) exerts a significant dampening effect on the volatility of economy wide inflation.

The model contains predictions that are consistent with most relevant empirical facts highlighted in the recent industrial organization literature concerning the dynamic distribution of firms' size, productivity, markups, market entry and exit flows, etc. (see e.g. Autor, Dorn, Katz, Patterson, and Van Reenen, 2019). In particular, in the model, firms in the upper echelons of the TFP distribution display higher market shares and markups as a reflection of their technological advantage. But market concentration may also stem from changes in the barriers to entry or in the elasticity of substitution between varieties of goods, which implies that market shares of technologically advanced firms and their markups might move in opposite directions. In our model, the effect of polarization in market shares on the coefficient of the Phillips curve is independent of the causes of concentration, whether "good" or "bad" in the terminology of Covarrubias, Gutiérrez and Philippon (2019), and hence on the evolution of other indicators of market power. In this way, the model offers robust predictions about the connection between the rising degree of polarization in many industries and recent inflation dynamics that fit well the existing evidence.

The paper is organized as follows. Section 2 revisits the most relevant facts about the dynamics of the industrial structure in the U.S. and other advanced economies. Section 3 presents the model and its calibration. In Section 4 we use the model to simulate the effect of steady state changes in some critical structural parameters that

\footnotetext{
${ }^{1}$ Weng and Werning (2020) look at the effect on price stickiness of strategic pricing under a more general class of preferences. Here we shall stick to the most conventional approach in New Keynesian DSGE models with exogenous elasticity of substitution.
} 
induce a stronger market concentration in sales, and investigate the consistency of the model's predictions and the facts discussed in Section 2. In Section 5 we derive the Phillips curve in the model and explore the mechanism that softens the response of inflation to exogenous shocks. Section 6 concludes.

\section{Inflation and the industrial structure: Main facts.}

Numerous studies have reported a surprisingly low volatility of inflation since the nineties, along a period in which years of macroeconomic stability have alternated with others of unusually large booms and busts. Del Negro, Lenza, Primiceri, and Tambalotti (2020) summarize the potential explanations for this phenomenon and try to disentangle among the following candidates. A first possible explanation points out that business cycle fluctuations and related measures (cyclical unemployment, the output gap, unit labor costs, etc.) are now more stable than they used to be before the 1990s. Alternatively it could be the case that the link between labor market slack and wage inflation might have weakened since then, so that the reduced volatility of inflation would just reflect the stability of wages. Finally, even if none of the above held true, price inflation might have been progressively disconnected from business cycle fluctuations either because of the enhanced capacity of monetary authorities to control inflation (policy hypothesis) or as a result of a genuine reduction in the elasticity of inflation in the face of shocks to firms' marginal costs (slope hypothesis).

Del Negro, Lenza, Primiceri, and Tambalotti (2020) find compelling empirical evidence in favor of the previous last hypothesis and conclude that, although changes in monetary policy making may have contributed to some extent, the main factor behind the progressively muted response of inflation since the 1990s is a reduction in the slope of the Phillips curve. Blanchard (2016) also finds that the response of inflation to variations in the unemployment rate has declined significantly since the 1980s in the U.S. If prices have become less sensitive to changes in marginal costs, while the wage-unemployment trade off has not changed significantly over these years, this implies that firms are absorbing in their markup the fluctuations of their marginal costs, which suggests a structural change in firms' pricing patterns. Furthermore, consistent with the results by Stock and Watson (2019), this change in companies' pricing behavior, while quite generalized, has nonetheless been heterogeneous across sectors, suggesting that some factors that are relevant in shaping pricing decisions may have evolved differently across sectors in recent decades.

In fact, the industrial organization literature has uncovered a number of persistent changes in the dynamic pattern of a number of important dimensions at the industry level over the last decades, including those related to the size, productivity, markups, and entry and exit dynamics (see e.g. Syverson 2004, 2011; Van Reenen, 2018; Bartelsman, Haltiwanger and Scarpetta, 2013). The following list summarizes the 
main empirical facts about the previous dimensions unveiled over the recent years.

Fact 1. Sustained increases in concentration in most industries, both in the U.S. and in other OECD countries, in the last two or three decades. Autor, Dorn, Katz, Patterson, and Van Reenen (2019) find an increase in concentration as measured by the percentage of sales of the bigger competitors in each sector of the U.S. economy since 1980-1990. This effect is substantial in the case of the market share of the largest firms, which would have risen between 20 and 100 percent above the levels observed at the beginning of the sample period. Similar results are reported by Covarrubias, Gutiérrez and Philippon (2019) and Grullon, Larkin, and Michaely (2019). Andrews, Criscuolo,and Gal (2016) report an increase in concentration in favor of the top firms across sectors in OECD economies, whereas Bajgar, Berlingieri, Calligaris, Criscuolo, and Timmis (2019) find that concentration has risen significantly since the early 2000s in 75 percent of all industries (defined at two digit level) in Europe, Canada and the U.S. These authors also conclude that the rise in concentration is a generalized pattern across many advanced economies.

Fact 2. Concentration has been stronger in output than in employment and the labor share has fallen in many sectors in advanced economies. The labor share is lower, and has even fallen, in the case of those firms whose market share has increased, so the observed aggregate pattern is largely due to the reallocation of sales across firms rather than a general fall in the labor share within incumbent firms. Thus, the fall in the labor share that is documented in many sectors in advanced economies is mostly accounted for by a composition effect (Kehrig and Vincent, 2018). Autor, Dorn, Katz, Patterson, and Van Reenen (2018), and Siebale, Suedekum, and Woessner, (2020) report a similar pattern in industries of OECD countries.

Fact 3. There has been an increase of the level of heterogeneity (polarization) among firms in some important dimensions. Akcigit and Ates (2019) report a rise in the productivity gap between firms at the technological frontier and the rest in the U.S. Also Berlingueri, Blanchenay and Criscuolo (2017) and Andrews, Criscuolo, and Gal (2015) find a similar pattern for firms in OECD countries in which the distance between the most and least productive firms in the same country and sector has increased by 12.8 percent for labour productivity and by 14 percent in the case of TFP.

Fact 4. De Loecker and Eeckout (2017) and De Loecker, Eeckhout, and Unger (2020) have reported a global pattern of growth of markups by up to 60 per cent or more in Europe and North America in the last 30-40 years. This occurs mostly at the top of the markup distribution within most industries. Within narrowly defined industries, there is a positive relationship between markups and firm size (market share). 
Fact 5. Despite some composition effects, there has been a steady decline in firm entry in most industries across OECD economies (OECD, 2019), and in particular in the U.S. (Akcigit and Ates, 2019; Decker, Haltiwanger, Jarmin and Miranda, 2016).

Fact 6. Gutiérrez, Jones and Philippon (2019) and Eggertsson, Robbins, and Wold (2018), report a generalized fall in investment rates in many advanced economies since 2000. This has occurred in particular in industries where concentration has increased more and despite the fall in interest rates and other financial costs for most firms.

Fact 7. The decline in the labor share is accompanied by a fall in capital share. Lower labor and capital share have in turn been compensated by an increase in the participation of profits in total income (Barkai, 2019; De Loecker and Eeckout, 2017; Eggertsson, Robbins, and Wold, 2018).

Fact 8. The intensity of the response of output to technology shocks has moderated. This pattern is documented by De Loecker and Eeckout (2017) and Decker, Haltiwanger, Jarmin, and Miranda (2014) who report a moderation in the response of firms to exogenous productivity shocks in recent decades, compatible with the observed Great Moderation in output volatility in advanced economies.

While the relevance of the previous trends is well acknowledged as key determinants of an economy's long-term macroeconomic performance, their impact on short and medium-run fluctuations is less so. In the next section we set up a model that helps us understand (part of) the recent weakening of the response of inflation to shocks to the marginal costs as a result of changes in the distribution of firms witnessed over the last decades. Interestingly, the model offers a number of predictions that square remarkably well with most of the previous facts. In this way, the model's main prescriptions link the growing body of the empirical literature on firms' dynamics outlined above with some questions that are lying at the core of the current macroeconomic and monetary policy discussions.

\section{The Model}

Standard Dixit-Stiglitz monopolist competition models in the macro literature predict that an increase in the sustitutability among varieties enhances competition, hence, reducing markups and firms' profits and increasing welfare. In this setup there is a sufficiently large number of homogeneous firms who operate without taking into account the response of the others to their own price and production decisions. Also, market concentration and market power are positively related. Fewer firms implies weaker competition and higher markups. When the number of firms increases, sustitutability among varieties and competition intensify leading to lower market concentration. In general, in this class of models, there is no connection between the 
slope of the Phillips curve and the intensity of competition. ${ }^{2}$ Transitory changes in the markup are typically added to the Phillips curve as exogenous shocks affecting inflation. Yet, in the light of the substantial and persistent increases in markups found in the empirical literature over the last two decades, the standard model has difficulties in accounting for the low level and volatility of inflation observed recently (De Loecker and Eeckout, 2017).

An important feature of the industrial structure, often overlooked in the macro literature, is that even within narrowly defined industries, firms are heterogeneous in the efficiency with which they use their factors of production. Syverson $(2004,2011)$ estimates that on average across U.S. industries, labor productivity of top firms (90th percentile of the distribution) is up to four times that of the firms at the bottom (10th percentile). This has led authors like Ghironi (2017) to argue that "the standard toolkit for macroeconomic analysis of fluctuations and policy must be extended to include producer-level dynamics of entry and exit, heterogeneity across firms, and the implications of these dynamics and heterogeneity for the macroeconomy".

The implications of heterogeneity may be substantial. Heterogenous firms will naturally differ in their market share, which will no longer depend exclusively on the number of firms in the industry. Also, the notion of market power is now fuzzier since market shares and the markup may move together or in the opposite direction, depending on the drivers behind the dynamics of the industry structure. In industries characterized by firm heterogeneity stemming from technological differences a technological improvement by the most efficient firms allows them to increase their market share and their markup simultaneously (Siebale, Suedekum, and Woessner, 2020). On the other hand, if the varieties produced by different firms become closer substitutes so that competition intensifies, there would be an across-the-board reduction in the markup, but more efficient firms will still be capable of gaining market share, at the cost the less efficient ones. In this case, larger firms' markups and concentration evolve in opposite directions. Firms using more efficient technologies, that allow them to set lower prices than their close competitors, are capable of earning large profits by exploiting their market share in total sales, despite their low markups. On the other hand, the market position of each firm might be eroded by new entrants or by other incumbents investing in innovation and in more efficient technologies.

Since the market share of firms depends on their cost advantage, and not only on barriers to entry or variety differentiation, firms' price decisions and the response of

\footnotetext{
${ }^{2}$ In fact, the elasticity of substitution among varieties may enter the slope of the Phillips curve if either we asume that price rigidities are modeled as in the menu cost model, or if we consider explictely the differences between the firm's expected future markup and its aggregate value in the standard Calvo model. These alternative modeling choices predict correlations among the elasticty of substituion and the slope of the Phillips curve with opposite signs. Besides, in elther case, the channel through which this elasticity affects inflation is different from the one in this paper.
} 
other competitors to a given company's prices is of critical importance. As Syverson (2018) puts it, these industries are characterized by a higher responsiveness of market shares to cost differences. As a consequence, the link between competition and prices (inflation) is more complex.

In this section we put forward a framework that accommodates some of the previous features and departs from the standard DSGE model in two important ways. First, we assume Bertrand competition in prices, so that firms set prices taking into account the response of other firms' prices, and hence of their own market share. Second, we allow for entry and exit in a model with different technology (TFP) classes, across which firms may move (up, down or out) endogenously. We discuss the industrial structure in detail and present the full equilibrium in Appendix II. A more detailed description of the complete model is available upon request.

\subsection{Market structure}

There are two final goods, one destined to create new firms, produced using intermediate goods from the new entrants $\left(y_{t}^{d E}\right)$, and another for the market $\left(y_{t}^{d H}\right)$. Production of $y_{t}^{d H}$ takes place at three differentiated levels and the structure of the model economy is comprised of producers and retailers (aggregators) as follows:

1. At the bottom, intermediate producers (IP), indexed by $i$, are organized in different productivity categories (i.e. characterized by different TFP levels) indexed by $s$, where $s=1,2, \ldots N$, and $N$ is fixed. These firms produce varieties $y_{i t}^{P s}$ that are imperfect substitutes of each other and sell them in an imperfectly competitive market at the flexible price $p_{i t}^{P s}$. Transitions of firms may occur across (adjacent) categories, as well as for entry and exit, so that the total number of IP firms as well as the number of them in each category may change endogenously. These transitions entail the payment of some fixed costs.

2. In each productivity category $s$ there is a set of intermediate retailers (IR) indexed by $z$ that purchase the varieties in their category and bundle them into a new good, $y_{z t}^{s}$, that is sold at the price $p_{z t}^{s}$. These retailers sell their newly produced variety $y_{z t}^{s}$ to the aggregate retailers (see below) in a monopolistically competitive market and face Calvo rigidities in price setting. Unlike intermediate producers, when setting their price these retailers take into account the fact that they compete with other IR firms, in their own and also in other size categories, so their pricing behaviour is conditioned by strategic interactions à la Bertrand. Notice that IR firms operating in more productive categories are able to get their inputs (varieties $y_{i t}^{P s}$ ) at a lower price, so they operate under lower marginal cost than intermediate retailers in less productive categories. This group is composed of $N^{R}$ firms in each type $s$, who solve a two-stage problem. 
3. Finally, there is a group of aggregate retailers (AR) that purchase the varieties of intermediate retailer goods from all different categories $\left(y_{z t}^{s}\right)$ at the price $p_{z t}^{s}$ and bundle them into a final good $\left(y_{t}^{d H}\right)$ used for consumption, investment, etc. These AR firms sell their output at the flexible price $p_{t}$ in a competitive market. The number of final good aggregators is also fixed.

\subsection{Pricing}

The first novelty included in the model is in the price setting of intermediate retailers. Before getting to it we next explain the price setting behaviour of aggregate retailers and intermediate good producers.

\section{Aggregate retailers:}

The group of retailers at the aggregate level bundle together all the intermediate retailer goods $z$ of each productivity class $s$ (with price $p_{z t}^{s}$ and production $y_{z t}^{s}$ ) into the final good, $y_{t}^{d H}$, that will be used for consumption, investment, etc., demanding from each intermediate retailer's production a volume given by

$$
y_{z t}^{s}=\left(\frac{p_{z t}^{s}}{p_{t}}\right)^{-\varepsilon} \frac{y_{t}^{d H}}{N N^{R}}
$$

and setting the aggregate price

$$
p_{t}=\frac{\varepsilon}{\varepsilon-1}\left[\left(N N^{R}\right)^{-1} \sum_{s=1}^{N} \sum_{z=1}^{N^{R s}}\left(p_{z t}^{s}\right)^{1-\varepsilon}\right]^{\frac{1}{1-\varepsilon}} .
$$

\section{Intermediate good-producers:}

Intermediate good producers compete monopolistically but face no price rigidities. Therefore, they set prices as a constant mark up over their marginal costs, which are proportional to the idiosyncratic component, while they all set the same capitallabour ratio $\left(\frac{k_{t-1}^{s}}{l_{t}^{d s}}=\frac{\alpha_{s}}{1-\alpha_{s}} \frac{w_{t}}{r_{t}}\right)$

$\frac{p_{i t}^{P s *}}{p_{t}}=\frac{\varepsilon}{\varepsilon-1} m c_{i, t}^{P s}=\frac{\varepsilon}{\varepsilon-1} \frac{m c_{t}^{P s}}{a_{t}^{i, \gamma}}=\left[\left(\frac{1}{\alpha_{s}}\right)^{\alpha_{s}}\left(\frac{1}{1-\alpha_{s}}\right)^{1-\alpha_{s}} \frac{r_{t}^{\alpha_{s}} w_{t}^{1-\alpha_{s}}}{A_{t}^{s}}\right] \frac{1}{a_{t}^{i, \gamma}}$ for $s=0, \ldots, N$

Intermediate retailers (IR):

The novelty in price-setting in the model locates in the group of intermediate retailers, who set their prices à la Bertrand. This group is composed of a continuum $z$ of wholesale firms of each type $s$, who solve a two-stage problem. In the first stage, each retailer $z$ buys inputs from all the intermediate producers in its class $\left(y_{z i t}^{P s}\right)$ in order to minimize costs, taking input prices $p_{i t}^{P s}$ as given, as follows 


$$
\begin{gathered}
\min _{y_{z i t}^{P s}} \sum_{i=1}^{N^{s}} p_{i t}^{P s} y_{z i t}^{P s} \\
\text { s.t.: } y_{z t}^{s}=\left[\left(N^{s}\right)^{-\frac{1}{\varepsilon}} \sum_{i=1}^{N^{s}}\left(y_{z i t}^{P s}\right)^{\frac{\varepsilon-1}{\varepsilon}}\right]^{\frac{\varepsilon}{\varepsilon-1}}
\end{gathered}
$$

The intermediate retailers take into account the marginal cost of intermediate good producers, together with their marginal cost $\left(m c_{t}^{s}=\frac{\varepsilon}{\varepsilon-1} \frac{m c_{t}^{P s}}{\bar{a}_{t}^{s}}\right)$ of production to set their optimal demand of intermediate products ${ }^{3}$

$$
y_{z i t}^{P s}=\left(\frac{a_{t}^{i, \gamma}}{\bar{a}_{t}^{s}}\right)^{\varepsilon} \frac{y_{z t}^{s}}{N_{t}^{s}}=\left(\frac{a_{t}^{i, \gamma}}{\bar{a}_{t}^{s}}\right)^{\varepsilon} \frac{\left(v_{t}^{p s}\right)^{-\varepsilon} y_{t}^{d H}}{N N^{R} N_{t}^{s}},
$$

where we have defined the dispersion of productivity as $\left(\bar{a}_{t}^{s}\right)^{\varepsilon-1}=\frac{1}{N_{t}^{s}} \int_{1}^{N_{t}^{s}}\left(a_{t}^{i, \gamma}\right)^{\varepsilon-1} d i$. That is, the demand posed by each retailer of an intermediate good depends positively on how its idiosyncratic technology $\left(a_{t}^{i}\right)$ compares to the average $\left(\bar{a}_{t}^{s}\right)$, while the marginal costs of retailers are equal to the average marginal cost of intermediate producers scaled up by the markup set by the later group . Note that retailers purchasing goods from more productive firms will be able to set lower markups and prices, since the marginal cost of intermediate producers in those groups $s$ is a negative function of the technology level that firms acquire when they enter that $\operatorname{group}\left(A_{t}^{s}\right)$.

In the second stage, each of these retailers set the price, $p_{z t}^{s}$, that maximizes discounted real profits, taking the input prices and factors demand as given. We assume that retailers in each size group choose the optimal price according to a Calvo's mechanism. ${ }^{4}$ That is, in each period, a fraction $\left(1-\theta_{p}^{s}\right)$ of retailers can change their prices. All other retailers index their prices to either past inflation or steady state inflation, which is controlled by the parameter $\chi_{s} \in[0,1]$, where $\chi_{s}=0$ represents indexation to steady state inflation only and $\chi_{s}=1$ corresponds to total indexation to past inflation. Optimizing retailers $z$ in class $s$ solve the following maximization problem

$$
\begin{gathered}
\max _{p_{z t}^{s}} \mathbb{E}_{t} \sum_{\tau=0}^{\infty}\left(\beta \theta_{p}^{s}\right)^{\tau} \frac{\lambda_{t+\tau}}{\lambda_{t}}\left\{\left(\prod_{r=1}^{\tau} \frac{\Pi^{1-\chi_{s}} \Pi_{t+r-1}^{\chi_{s}}}{\Pi_{t+r}} \frac{p_{z t}^{s}}{p_{t}}-m c_{t+\tau}^{s}\right) y_{z t+\tau}^{s}\right\}, \\
\text { s.t.: } y_{z t+\tau}^{s}=\left(N N^{R}\right)^{-1}\left(\prod_{r=1}^{\tau} \frac{\Pi^{1-\chi_{s} \Pi_{t+r-1}^{\chi_{s}}}}{\Pi_{t+r}} \frac{p_{z t}^{s}}{p_{t}}\right)^{-\varepsilon} y_{t+\tau}^{d H}, \quad \text { for } s=1, \ldots, N \\
\quad p_{t}=\left[\left(N N^{R}\right)^{-1} \sum_{s=1}^{N} \sum_{z=1}^{N^{R s}}\left(p_{z t}^{s}\right)^{1-\varepsilon}\right]^{\frac{1}{1-\varepsilon}},
\end{gathered}
$$

\footnotetext{
${ }^{3}$ The superscript $s$ reflects the fact that marginal cost differs across categories, but it does not have the $z$ subscript since it is independent of retailers $z$ characteristics.

${ }^{4}$ Assuming Rotemberg (1982) pricing yields very similar results (both qualitatively and also quantitatively under an equivalent calibration). Apendix III summarizes the derivation of the Philips curve in the model with adjustement costs, firm heterogeneity and Bertrand competition. An appendix with the quantitative results in this case is available upon request.
} 
where the discount factor takes into account the marginal value of a dollar to the household, which is treated as exogenous by the firm. In a symmetric equilibrium, the optimal (relative) price that solves this problem $\left(\Pi_{t}^{s *}=\frac{p_{t}^{s *}}{p_{t}}\right)$ is given by

$$
\Pi_{t}^{s *}=\frac{\eta_{p z t}^{s}}{\eta_{p z t}^{s}+1} \frac{\mathbb{E}_{t} \sum_{\tau=0}^{\infty}\left(\beta \theta_{p}^{s}\right)^{\tau} \frac{\lambda_{t+\tau}}{\lambda_{t}}\left(\prod_{r=1}^{\tau} \frac{\Pi^{1-\chi_{s} \Pi_{t+r-1}^{\chi_{s}}}}{\Pi_{t+r}}\right)^{-\varepsilon} m c_{t+\tau}^{s} y_{t+\tau}^{d H}}{\mathbb{E}_{t} \sum_{\tau=0}^{\infty}\left(\beta \theta_{p}^{s}\right)^{\tau} \frac{\lambda_{t+\tau}}{\lambda_{t}}\left(\prod_{r=1}^{\tau} \frac{\Pi^{1-\chi_{s} \Pi_{t+r-1}^{\chi_{s}}}}{\Pi_{t+r}}\right)^{1-\varepsilon} y_{t+\tau}^{d H}},
$$

where $\eta_{p z t}^{s}$ is the price elasticity of demand that each retailer faces that can be expressed as a function of the elasticity of the aggregate price to the intermediate retailer price:

$$
\eta_{p z t}^{s}=\frac{\partial y_{z t+\tau}^{s}}{\partial p_{z t}^{s}} \frac{p_{z t}^{s}}{y_{z t+\tau}^{s}}=-\varepsilon\left(1-\frac{\partial p_{t}}{\partial p_{z t}^{s}} \frac{p_{z t}^{s}}{p_{t}}\right)
$$

where

$$
\frac{\partial p_{t}}{\partial p_{z t}^{s}} \frac{p_{z t}^{s}}{p_{t}}=s_{t}^{s}=\frac{p_{z t}^{s} y_{z t}^{s}}{p_{t} y_{t+\tau}^{d H}}
$$

This aggregate price elasticity, in turn, equals the (nominal) market share of intermediate retailers and reflects that each individual firm takes into account the incidence of its own pricing decisions on the aggregate price, because these affect its own market share. This term is known in the literature as the strategic competition effect (see Etro and Colciago, 2010). If this strategic component is zero, then the price elasticity is constant, while if positive, the intensity of the strategic component will depend on the retailer's market share, which in turn is a function of the two key variables of the model: the number of firms in the market and the retailer's own optimal relative price, according to the following expression

$$
s_{t}^{s}=\left(N N^{R}\right)^{-1}\left(\frac{p_{z t}^{s}}{p_{t}}\right)^{1-\varepsilon},
$$

and hence $\eta_{p z t}^{s}$ can be expressed as

$$
\eta_{p z t}^{s}=-\varepsilon\left(1-\left(N N^{R}\right)^{-1}\left(\frac{p_{z t}^{s}}{p_{t}}\right)^{1-\varepsilon}\right),
$$

The expression in (6) is key to understand the mechanism governing the response of inflation to different shocks. If firms are homogeneous, the strategic interaction is second order since the steady state market shares (and the elasticity of demand) are constant and identical across firms. In fact, in this case $\eta_{p z}^{s}$ is equal to the inverse of the number of firms, because their steady state optimal relative price is $\frac{p_{z}^{s}}{p}=1$ times the elasticity of substitution (and close to $\varepsilon$ if $N N^{R}$ is large). When there is firm heterogeneity, the strategic interaction component varies across types of firms 
and thus becomes relevant at the time of setting prices, since in this case individual pricing decisions affect market shares and thus the elasticity of the individual firm's demand schedule. In particular, in the case explained here, with two types of firms, small and less productive firms face a higher steady state relative price $\frac{p_{z}^{s}}{p}>1$ and a smaller market share, both relative to larger firms and to the situation that would prevail in the case of homogenous firms, making the steady state elasticity of their demand greater. On the contrary, large and more productive firms set lower prices, $\frac{p_{z}^{s}}{p}<1$, and enjoy greater steady state market share, both relative to smaller firms and with respect to what would obtain in the case of homogenous firms, so that the elasticity of their demand is smaller, an aspect that has a significant effect on their price decisions. Therefore, small (large) firms tend to adjust their prices by a larger (smaller) amount after a shock both relative to large (small) firms and to the homogenous firm case of reference.

$$
\text { Homogeneous firms } \frac{p_{z}^{s}}{p}=1 \rightarrow\left|\eta_{p z}^{s}\right|=\varepsilon\left(1-\frac{1}{N N^{R}}\right) \approx \varepsilon,
$$

Heterogeneous firms:

$$
\begin{aligned}
& \text { small } \frac{p_{z}^{s}}{p}>1 \rightarrow\left|\eta_{p z}^{\text {small }}\right|=\varepsilon\left(1-\frac{1}{N N^{R}\left(\frac{p_{z}^{s}}{p}>1\right)^{\varepsilon-1}}\right)>\eta_{p z}^{\text {homogenous }} \\
& \text { large } \frac{p_{z}^{s}}{p}<1 \rightarrow\left|\eta_{p z}^{\text {large }}\right|=\varepsilon\left(1-\frac{1}{N N^{R}\left(\frac{p_{z}^{s}}{p}<1\right)^{\varepsilon-1}}\right)<\eta_{p z}^{\text {homogenous }} .
\end{aligned}
$$

It is convenient to rewrite equation (4) recursively through the use of the auxiliary variables $g_{t}^{s 1}$ and $g_{t}^{s 2}$ in terms of the following three equations

$$
\begin{aligned}
g_{t}^{s 1} & =d_{t} c_{t}^{-\sigma} \frac{\varepsilon}{\varepsilon-1} m c_{t}^{s} y_{t}^{d H}+\beta \theta_{p}^{s} \mathbb{E}_{t}\left(\frac{\Pi^{1-\chi_{s}} \Pi_{t}^{\chi_{s}}}{\Pi_{t+1}}\right)^{-\varepsilon} g_{t+1}^{s 1}, \\
g_{t}^{s 2} & =d_{t} c_{t}^{-\sigma} \Pi_{t}^{s *} y_{t}^{d H}+\beta \theta_{p}^{s} \mathbb{E}_{t}\left(\frac{\Pi^{1-\chi_{s}} \Pi_{t}^{\chi_{s}}}{\Pi_{t+1}}\right)^{(1-\varepsilon)}\left(\frac{\Pi_{t}^{s *}}{\Pi_{t+1}^{s *}}\right) g_{t+1}^{s 2}, \\
\Pi_{t}^{s *} & =\frac{\varepsilon}{\varepsilon-1}\left[\frac{(\varepsilon-1)\left(1-\left(N N^{R}\right)^{-1}\left(\Pi_{t}^{s *}\right)^{1-\varepsilon}\right)}{\varepsilon\left(1-\left(N N^{R}\right)^{-1}\left(\Pi_{t}^{s *}\right)^{1-\varepsilon}\right)-1}\right] \frac{g_{t}^{s 1}}{g_{t}^{s 2}}=\frac{\eta_{p t}^{s}}{\eta_{p t}^{s}+1} \frac{g_{t}^{s 1}}{g_{t}^{s 2}}=\frac{\varepsilon\left(1-s_{t}^{s}\right)}{\varepsilon\left(1-s_{t}^{s}\right)-1} \frac{g_{t}^{s 1}}{g_{t}^{s 2}} .
\end{aligned}
$$

Expression (9) makes clear that firms set their optimal (relative) price $\left(\Pi_{t}^{s *}\right)$ as a markup $\left(\mu_{t}^{d s}=\frac{\eta_{p t}^{s}}{\eta_{p t}^{s}+1}\right)$ over the discounted sequence of future marginal costs $\left(\frac{g_{t}^{s 1}}{g_{t}^{s 2}}\right)$. $\mu_{t}^{d s}$ can be named "desired markup", since it is similar to the one prevalent under no price rigidities, except that in our model the elasticity of demand is not constant, but instead is decreasing in the number of firms producing in the economy, while increasing in the firm's market share,

$$
\mu_{t}^{d s}=\frac{\varepsilon}{\varepsilon-1}\left[\frac{(\varepsilon-1)\left(1-\left(N N^{R}\right)^{-1}\left(\Pi_{t}^{s *}\right)^{1-\varepsilon}\right)}{\varepsilon\left(1-\left(N N^{R}\right)^{-1}\left(\Pi_{t}^{s *}\right)^{1-\varepsilon}\right)-1}\right]=\frac{\varepsilon\left(1-s_{t}^{s}\right)}{\varepsilon\left(1-s_{t}^{s}\right)-1} .
$$


Notice that the desired markup in (10) is endogenous in the model since it depends on the price set by firms, $\Pi_{t}^{s *}$, and also on the TFP class the firm has optimally chosen, $s$. When there is no heterogeneity effect, $\frac{\partial p_{t}}{\partial p_{z t}^{s}} \frac{p_{z t}^{s}}{p_{t}}=0$, the desired markup is constant and exogenous to the firm, as in the standard case $\left(\mu^{d}=\frac{\varepsilon}{\varepsilon-1}\right)$.

Finally, in a symmetric equilibrium, in every period, a fraction $1-\theta_{p}^{s}$ of retailers re-set optimally their price, $p_{t}^{s *}$, while the remaining fraction $\theta_{p}^{s}$ partially index their price by past inflation. Consequently, the aggregate price index for retailers of each size group $\left(p_{t}^{s}=\left[\left(N^{R}\right)^{-1} \sum_{z=1}^{N^{R s}}\left(p_{z t}^{s}\right)^{1-\varepsilon}\right]^{\frac{1}{1-\varepsilon}}\right)$ evolves as follows

$$
\Pi_{t}^{s *}=\left[\frac{\left(\widetilde{p}_{t}^{s}\right)^{1-\varepsilon}}{1-\theta_{p}^{s}}-\left(\frac{\Pi^{1-\chi_{s}} \Pi_{t-1}^{\chi_{s}}}{\Pi_{t}}\right)^{1-\varepsilon} \frac{\theta_{p}^{s}}{1-\theta_{p}^{s}}\left(\widetilde{p}_{t-1}^{s}\right)^{1-\varepsilon}\right],
$$

where $\widetilde{p}_{t}^{s}=\frac{p_{t}^{s}}{p_{t}}$, and the aggregate price index must satisfy the condition:

$$
1=\sum_{s=1}^{N} \frac{\left(\widetilde{p}_{t}^{s}\right)^{1-\varepsilon}}{N} \text {. }
$$

\subsection{Firm dynamics: Entry and transitions of intermediate producers}

The second novelty of the model is that it incorporates a complex market structure in which intermediate good producers experience endogenous entry and transitions amongst (adjacent) productivity types in the following manner.

Intermediate producers are organized in different productivity classes captured by the variable $A_{t}^{s}$, which is class but not firm specific. The total amount of IP firms in the market as well as the number of firms in each category is not fixed. Entry and exit flows as well as up-and-down transitions across the technological (and, hence, size) scale are endogenous. On the one hand, there is a large number of potential entrants, some of which decide optimally to enter the market. In such a case, these firms acquire the least productive general technology available (lowest $A_{t}^{s}=A_{t}^{0}$ ). On the other hand, incumbent firms may optimally upgrade or downgrade their technology. Without loss of generality and in order to keep the model tractable, we assume that firms can only move each period to either group immediately adjacent (i.e. at $t$, group $s$ only receives firms from groups $s-1$ and $s+1$ ). The main driver of this up-and-down dynamics is a non-persistent idiosyncratic productivity shock $\left(a_{i t}\right)$ that enters the firm production function as: $y_{i t}^{P s}=a_{i t}^{\gamma} A_{t}^{s}\left(k_{i t-1}^{s}\right)^{\alpha}\left(l_{i t}^{d s}\right)^{1-\alpha}$, where $\gamma$ is the elasticity of the iid component to output. This firm specific shock is drawn from a given distribution at the beginning of every period. To determine both the optimal entry and the upgrade/downgrade decisions we need to calculate the real value of an entrant and a producing firm.

The timing of events in the model is as follows. At the beginning of the period $t$ the distribution of firms across productivity groups $\left\{A_{t-1}^{s}\right\}$ is given and the idiosyncratic productivity shock $\left(a_{i t}\right)$ is revealed. Then firms decide whether to change 
their size and access to a different technology class or to stay at the one they were in at $t-1$. Then, the aggregate productivity shock is realized and firms set their demand for inputs and produce. At the end of the period, some firms in each category receive a death shock with probability $\delta^{F s}$. In order to determine the optimal transition decisions at the beginning of period $t$ we calculate the change in the value of the firm and compare it with the costs incurred in that process.

We denote by $v_{i t}^{s}$ the value of firm $i$ of size $s$ at the beginning of period $t$, before dividends are paid. Let $s=0$ index the class of potential entrants with value $v_{t}^{0}$; firms will enter until their value is sufficient to pay for the the entry costs, which are proportional to the marginal cost of producing: $f_{t}^{0} m c_{t}^{0}$. The current value of potential entrants is equal to the discounted value of the firm that enters at $t$ and starts producing at $t+1$ in the least productive class $s=1$, that is ${ }^{5}$

$$
v_{t}^{0}=\mathbb{E}_{t} \Lambda_{t+1}\left(1-\delta^{F 0}\right) v_{t+1}^{1}=f_{t}^{0} m c_{t}^{0}
$$

where $\Lambda_{t+1}=\beta \frac{\lambda_{t+1}}{\lambda_{t}}$ is the discount factor of households, who own the firms, and $\delta^{F 0}$ is the probability of the firm being hit by a death shock once it has paid the entry cost but before it has started producing at all. We have dropped the $i$ subscript, since this problem is independent of the firm characteristics others than the size, captured by the superscript 0 .

Before solving for the value of incumbent firms, we first need to explain the growth process. Firm productivity is made of two components: A general technology of level, $A_{t}^{s}$, which requires a fixed cost per period $F_{t}^{s}$, and a sunk investment $f_{t}^{s}$, that displays persistence, and an idiosyncratic i.i.d. shock, $a_{t}^{i}$, which is drawn at the beginning of every period from the distribution $F(i) .{ }^{6}$ Therefore, once the individual productivity is revealed, firms decide whether to buy a superior general technology $\left(A_{t}^{s+1}\right)$ paying $f_{t}^{L s+1}$, to remain as they are, or to move to a lower class $\left(A_{t}^{s-1}\right)$ receiving a disinvestment payment $\left(f_{t}^{S s-1}\right)$. In so doing firms compare the expected gains from growth/or downgrade with the sunk cost and with the differences in fixed costs of production. ${ }^{7}$

Let us define $a_{t+1}^{L s}$ as the realization of the idiosyncratic productivity shock such that a firm in class $s$ is indifferent between moving up to $s+1$ and staying at $s$; every firm with an idiosyncratic draw above $a_{t+1}^{L s}$ will chose to upgrade. Likewise, there is a lower threshold $a_{t+1}^{S s}$ such that a firm is indifferent between keeping using

\footnotetext{
${ }^{5}$ The value of firms can be defined at the end of period (like in Bilbiie, Ghironi and Melitz, 2012), because entrants do not start to produce until the following period, or at the beginning (like in Bergin, Feng and Lin (2016)), because entrants start to produce immediately. In our case we define it at the beginning of the period to make it consistent with the size decision, which is taken at that moment. The value of entrants is equal to the value of producing firms with lowest technology, since the surviving entrants join this group.

${ }^{6}$ Fixed costs per period $F_{t}^{s}$, are necessary to have a non-degenerate distribution of firms in each size/general technology level. The sunk investment to grow $f_{t}^{L s}$ or the capital gain when downgrading $f_{t}^{S s}$ are necessary to have different thresholds for upgrading and downgrading.

${ }^{7}$ This payment would be equivalent to receiving the residual value from liquidating some assets when downgrading.
} 
the technology of the class $s$ or moving downwards to a lower technology class $s-1$. Then, the value of incumbent firm $i$ of size $s$ at the beginning of period $t$, before dividends are paid, is

$$
\begin{gathered}
v_{i t}^{s}=d_{t}^{v F s} a_{t}^{i, \gamma(\varepsilon-1)}-F_{t}^{s}+\mathbb{E}_{t} \Lambda_{t+1}\left(1-\delta^{F s}\right)\left(v_{t+1}^{s+1} \int_{a_{t+1}^{L s}}^{1} d i+v_{t+1}^{s-1} \int_{0}^{a_{t+1}^{S s}} d i+v_{t+1}^{s} \int_{a_{t+1}^{S s}}^{a_{t+1}^{L s}} d i\right) \\
e_{t}^{s}=\mathbb{E}_{t} \Lambda_{t+1}\left(1-\delta^{F s}\right)\left(v_{t+1}^{s+1} \int_{a_{t+1}^{L s}}^{1} d i+v_{t+1}^{s-1} \int_{0}^{a_{t+1}^{S s}} d i+v_{t+1}^{s} \int_{a_{t+1}^{S s}}^{a_{t+1}^{L s}} d i\right),
\end{gathered}
$$

where we have made use of the fact that firm profits $\left(d_{i t}^{F s}\right)$ can be expressed as the average variable profit per firm $\left(d_{t}^{v F s}\right)$ times its idiosyncratic productivity $\left(a_{t}^{i, \gamma(\varepsilon-1)}\right)$, minus the fixed costs $\left(F_{t}^{s}\right) .{ }^{8}$ For the sake of simplicity, when solving the model we calibrate the parameter $\gamma=(\varepsilon-1)^{-1}$ to make profits linear in idiosyncratic productivity. In addition, $e_{t}^{s}$ is the end of period value of firm $i$ of size $s$, which is our measure of equity price. Note that all components of this expression are independent of the idiosyncratic productivity level except for the multiplicative term in front of the profits (we assume that firms take the average as given). The forward looking component of the equity price depends on the new draw from the underlying distribution which has a constant average, normalized to 1.

Then, the conditions determining firm demographics beyond entry will be

$$
\begin{gathered}
\text { Growth decision } v_{i t}^{s+1}-v_{i t}^{s} \geq f_{t}^{L s+1} \\
\text { Downsize decision } v_{i t}^{s}-v_{i t}^{s-1} \leq f_{t}^{S s-1} \\
\text { Exit decision } v_{i t}^{1} \leq f_{t}^{S 0}
\end{gathered}
$$

which result in the following thresholds:

$$
\begin{gathered}
\text { upgrade technology if } a_{i t} \geq a_{t}^{L s} \\
a_{t}^{L s}=\left[\frac{\left[\left(F_{t}^{s+1}+f_{t}^{L s+1}\right)-F_{t}^{s}\right]-\left(e_{t}^{s+1}-e_{t}^{s}\right)}{d_{t}^{v F s+1}-d_{t}^{v F s}}\right]^{\frac{1}{\varepsilon-1}} \\
\text { downgrade technology if } a_{i t} \leq a_{t}^{S s} \\
a_{t}^{S s}=\left[\frac{\left[F_{t}^{s}-\left(F_{t}^{s-1}+f_{t}^{S s-1}\right)\right]-\left(e_{t}^{s}-e_{t}^{s-1}\right)}{d_{t}^{v F s}-d_{t}^{v F s-1}}\right]^{\frac{1}{\varepsilon-1}}
\end{gathered}
$$

exit the market if

$$
0 \leq a_{t}^{S 1}=\left[\frac{F_{t}^{1}-f_{t}^{S 0}-e_{t}^{1}}{d_{t}^{v F 1}}\right]^{\frac{1}{\varepsilon-1}}
$$

${ }^{8}$ It can be shown that the profits of intermediate producers are equal to

$$
d_{i t}^{F s}=\left(\frac{p_{i t}^{s}}{p_{t}}-m c_{i t}^{s}\right) y_{i t}^{s}=\frac{1}{\varepsilon-1} m c_{i t}^{s} y_{i t}^{s}=d_{t}^{v F s} a_{t}^{i, \gamma(\varepsilon-1)}
$$


Given these decision rules, the dynamics of firms by class are given by

$$
N_{t+1}^{s}=\left[\begin{array}{c}
\left(\int_{a_{t+1}^{L s-1}}^{1} d i\right)\left(1-\delta^{F s-1}\right) N_{t}^{s-1} \\
+\left(\int_{0}^{a_{t+1}^{S s+1}} d i\right)\left(1-\delta^{F s+1}\right) N_{t}^{s+1}+\left(\int_{a_{t+1}^{S s}}^{a_{t+1}^{L s}} d i\right)\left(1-\delta^{F s}\right) N_{t}^{s}
\end{array}\right],
$$

and the total number of operating and thus dividend-yielding firms $\left(N^{H}\right)$ evolves as

$$
N_{t+1}^{H}=\sum_{s=1}^{N} N_{t+1}^{s}=\sum_{s=0}^{N}\left(1-\delta^{F s}\right) N_{t}^{s}
$$

\subsection{Calibration and steady state}

Without loss of generality, in our simulation exercises we will assume just two productivity categories $(1,2)$ over and above that of entrants (indexed by $s=0$ ). The model has 29 calibrated parameters, some of which determine the steady state solution (columns 1-3 of Table 3), while others affect only the model dynamics. These parameters have been calibrated either using consensus values taken from the literature or were chosen to reproduce some data moments. In particular, we aim at approximating the stylized facts of the industrial structure, as well as the main macroeconomic ratios of the euro area economy, as represented by the average of the four largest country members, in bold in the fourth column of Table 4 . The first block of these (top block in bold) refers to long run (steady-state) ratios of the whole economy, the second one refers to characteristics of entrant firms, while the last two blocks refer to characteristics of large and small firms.

Table 3. Baseline Calibration

$$
\begin{array}{lllll} 
& \multicolumn{2}{c}{\text { steady state parameters }} & \multicolumn{2}{c}{\text { dynamics parameters }} \\
\beta=.99 & \varepsilon=\varepsilon_{w}=10 & \varphi=6 & \kappa=.1 & \gamma_{y}=.125 \\
\vartheta=\sigma=1 & \alpha_{H}=.372 & \alpha_{E}=0 & \chi=\chi_{w}=.125 & \rho_{A}=.7 \\
\delta=\delta^{F}=.025 & A^{L}=1.9 & A^{S}=.9 & \theta_{p}=\theta_{w}=.896 & \rho_{m}=0 \\
f^{0}=.11 & f^{L 2}=2.05 & f^{S 1}=-1 & \gamma_{R}=.8 & \rho_{d}=.9 \\
f^{S 0}=-.19 & F^{1}=.024 & F^{2}=.51 & \gamma_{\pi}=1.7 & \rho_{m u}=.7
\end{array}
$$

First, it is worth noting that a model of firm entry with capital poses additional problems for determinacy and non-explosiveness of the solution, since entry might potentially generate increasing returns to capital. This problem can be circumvented by assuming that new entrants do not need capital to produce (see Bilbiie, Ghironi and Melitz, 2012), which allows for a wider parameter space but still more reduced than under the no capital accumulation case.

We start by setting the parameters that affect only the dynamics of the model (right Panel of Table 3). The parameters of the Taylor rule are set to the standard estimation results for the Euro area (Clarida, Galí, and Gertler, 2000). On the nominal side, the Calvo and the indexation to inflation parameters for prices and wages are similar to the values generally obtained for the euro area (Smets and Wouters, 2005), while a very small adjustment cost for investment $(\kappa)$ is assumed.

Then we set the parameters that affect mainly the economy-wide steady state 
ratios and the characteristics of entrants. The discount factor $\beta$ is consistent with an annualized real interest rate of 2.5 percent and an inflation objective of 2 percent, so that the steady state annual nominal interest rate $(R)$ is 4.5 percent. The depreciation rate of capital is consistent with an annual depreciation of 10 per cent. The calibration of utility parameters is quite standard, with log utility of consumption $(\sigma=1)$. The Frisch elasticity of labor supply is $1(1 / \vartheta)$ in line with the findings of the microeconomics literature (Browning, Hansen, and Heckman, 1999). The labor supply coefficient is set to 6 , while the elasticity of substitution between different types of intermediate goods produced $(\varepsilon)$ and between different labour types $\left(\varepsilon_{w}\right)$, implies a steady state markup of around 10 percent, both in line with estimated DSGE models (Fernández-Villaverde, 2010). The labour share of incumbents is set equal to the value in the data for the EA average, while the one of entrants is set to 1 . Finally, the firms' death rate $\delta^{F}$ is such that 10 percent of annual production is destroyed (Bilbiie, Ghironi and Melitz, 2012, and Bernard, Redding, and Schott, 2010). The entry cost $f^{E}$ is one of the main determinants of the characteristics of entrant firms. A low level of this parameter, 0.11, guarantees that entrant firms represent in the steady state a small share of production and employment, similar to the data.

The last set of parameters determines the differences across incumbent firms. In a simple model without heterogeneity, firms' productivity levels are set equal to the average $\left(A^{L}=A^{S}=1\right)$. This calibration delivers model steady state ratios for the share of consumption in final demand, the labour share and the capital to GDP ratio fairly close to the ones in the data, while entrant firms characteristics are well approximated, except for their size (see first column of the right hand side Panel of Table 4).

In the second column of the right hand side Panel of Table 4 we allow for differences across incumbents, by setting the fixed costs of production and the costs of upgrading/downgrading to match the proportion of large and small firms in the data (12 vs 88 per cent, respectively) as well as the probabilities of transition across these categories (0.4 per cent and 1.5 per cent, respectively). ${ }^{9}$ With respect to the firms' productivity differences between small and large, we set them initially at the values observed in the data for Spain, which is the country with the greatest polarization of the four considered, to then change them for the different exercises shown. This allows the model to match fairly well the observed size of low productivity firms and their share of the whole economy in terms of production and, to a lesser extent, employment, while matching slightly better the characteristics of entrants without worsening the economy-wide steady state ratios.

\footnotetext{
${ }^{9}$ This information is only available for Spain, Italy and the US as far as we are aware. Therefore, we set these probabilities close to the values obtained for Spanish manufacturing firms over the period 2001-2007, from the CBI dataset (Central de Balances Integrada), and for Italian manufacturing firms from Schivardi and Torrini (2004).
} 
Table 4. Stylized facts of firms by size model vs data

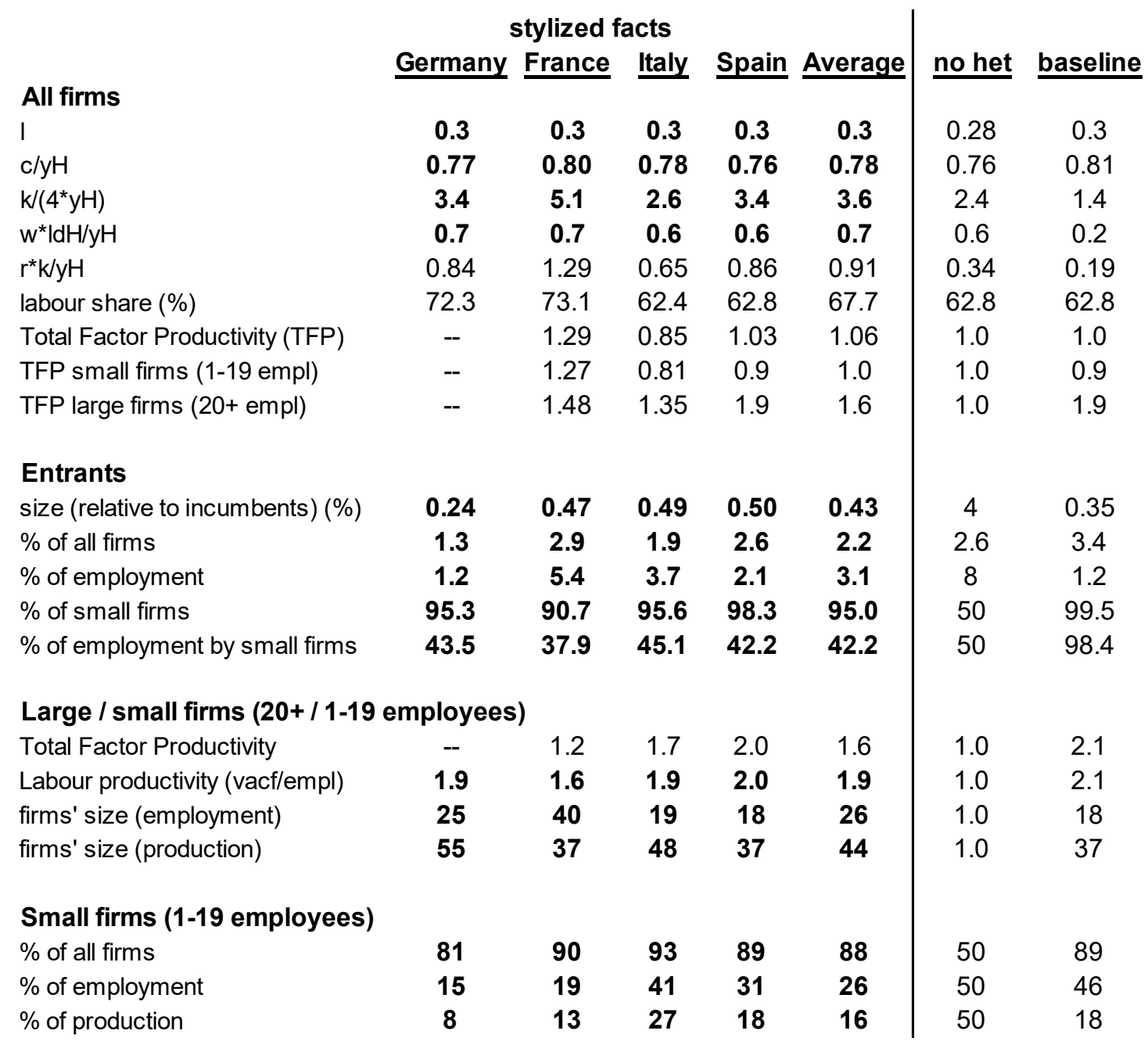

Source: Eurostat, OECD and authors own calculations.

\section{Industry structure, technology, competition and barriers to entry}

In this section we analyze to what extent our model is consistent with the empirical evidence related to the industry structure in advanced economies, discussed in Section 2. In the context of the calibrated version of the model in which we consider just two types of firms (small and large), we simulate the effects of changes in the main parameters of the model and look at the response of market shares, markups, investment and firm dynamics. ${ }^{10}$ We focus on the three main drivers of the current trends in market structures that have been put forward recently in the literature: polarization of technology -caused by an increase of the TFP of the most efficient firms $\left(A^{L}\right)$-, increase in competition -reflected through the rise of the sustitutability

\footnotetext{
${ }^{10}$ We set the steady state TFP level in the two firm classes to 0.9 and 1.9 , for the small and large firms, respectively, as estimated for Spanish data in Fernández and López (2014).
} 
among varieties $(\varepsilon)$-, and the rise of barriers to entry -through a varying magnitude of the fixed initial cost, $f^{0} .^{11}$

The permanent effects unchained by changes in the previous key parameters are depicted in Figures 1-6 below. Although the steady state effects are in some cases small, we still look at the qualitative direction of the impact, bearing in mind the empirical facts discussed in Section 2. The complexity of the model restricts significantly the range of values consistent with a solution for some parameters. In particular, the changes associated to the entry costs are small because the model only allows for small deviations from the baseline calibration of the fixed cost of entry.

Figure 1: Fact $1 \& 2$ - Market share of production \& employment

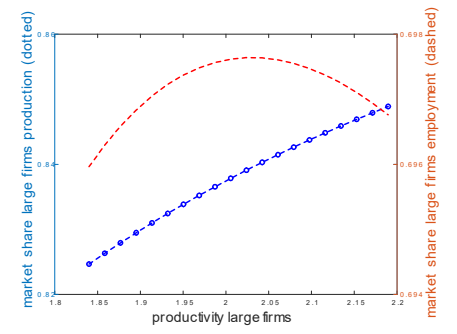

(a) Productivity large firms

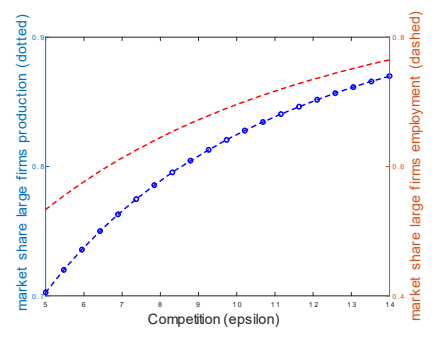

(b) Competition $(\varepsilon)$

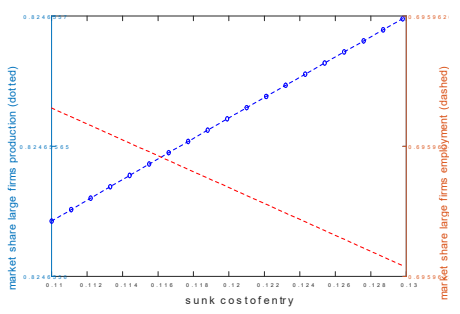

(c) Cost of entry

Fact 1: Generalized increase in market shares by large firms and polarization. Our model is consistent with sector polarization regardless of the underlying cause behind this pattern. All the three factors identified by Gutiérrez, Jones and Philippon (2019) for the U.S. economy (technology improvement, competition and entry barriers), contribute in the model to raise the market share in sales by larger firms, and thus to the polarization of the distribution of firms by size observed in the data (see dotted blue lines in Figure 1). As more productive firms become even more efficient, they are able to reduce their prices and gain a larger market share. Also, when varieties become closer substitutes to each other, more efficient firms are able to capture a larger fraction of the market. Finally, an increase in the entry costs also favors larger firms since the proportion of new (small) entrants falls. These results hold not only for the share of each firm but also when we restrict to the aggregate output of the class of more efficient firms.

All these three channels are present in expression (5) above, that describes the market share as a function of the number of firms, the relative price and the elasticity of substitution among varieties. The improvement in technology of most efficient firms reduces their relative price, $\frac{p_{z t}^{s}}{p_{t}}$, and the increase in the entry costs reduces the

\footnotetext{
${ }^{11}$ We have also analyzed the impact of changes in other parameters of the model like the sunk costs of upgrading or downgrading in the technology ladder by firms, changes in firms' death rate, etc. The impact on the most relevant features of the distribution of firms of changes in these parameters is small so that we do not present them here. They are available on request. The change in entry costs $\left(f^{0}\right)$ is also very tiny, which is reflected in small movements of the variables of interest. We depict them in the pictures for the sahe of completeness although we do not comment on them when their quantitative impacts is almost negligible.
} 
total number of firms, $N N^{R}$, both of which affect $s_{t}^{s}$ in the same direction. The increase in the elasticity of substitution is the factor that contributes to polarize the market most, since it pushes up or down the market share depending on whether the relative price of the firm is below (more efficient firms) or above (less efficient firms) 1.

Fact 2: Stronger concentration in sales than in employment and diminishing labor share of larger firms. The model predicts that concentration in employment proceeds at a lower pace than concentration in sales. In some circumstances they even move in opposite directions. In the model, the increase in the market share (blue dotted lines in Figure 1) may or may not be accompanied by a parallel increase in the share in employment (red dashed lines in Figure 1). When the market share increases due to competition, both forms of concentration move in the same direction and by similar magnitudes (Figure 1, panel b). A rise in entry costs moves sales concentration and employment concentration in opposite directions, which implies that bigger firms concentrate a lower proportion of total employment in the industry (Figure 1, right panel c).

When the increase in sales concentration is the result of a technological advantage, the share of employment by large firms remains roughly constant and even decays somewhat beyond some value of $A^{L}$ (Figure 1, left panel a). This implies that the labor share is again falling in those firms showing a technological advantage, consistent with the empirical evidence and with the superstar firm theory of Autor, Dorn, Katz, Patterson, and Van Reenen (2018), along which firms at the technological frontier end up employing a decreasing proportion of the labor force (scale without mass). ${ }^{12}$

Figure 2: Fact 3 - Aggregate Productivity gap among firms

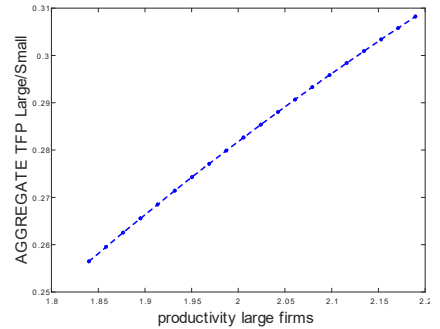

(a) Productivity large firms

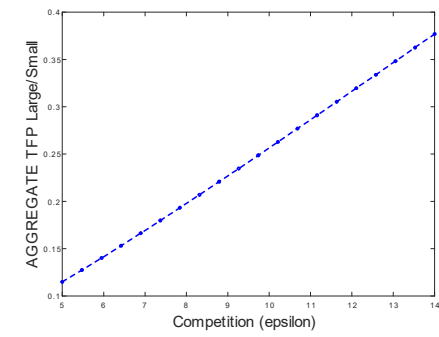

(b) Competition $(\varepsilon)$

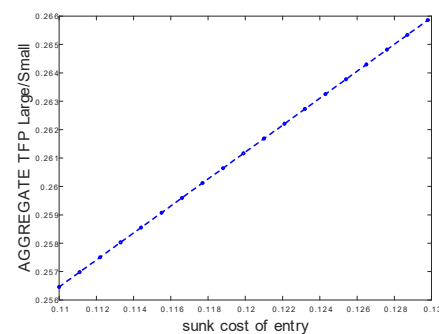

(c) Cost of entry

Fact 3: The productivity and TFP gap among firms has widened. Regardless of the cause behind the increase in sales concentration, shown in Fact 1 above, we observe that the distance in TFP between more efficient and less efficient firms widens when output concentration heightens (see Figure 2). The result in Figure 2.a stems directly from the increase in $A^{L}$, but the increase in TFP polarization caused by the rise in $\varepsilon$ (Figure 2.b) is less straightforward. The intensification of competition that widens the advantage of large firms incentivizes more firms to incur in the upgrading cost to acquire a technology of class $A^{L}$. So the group of efficient firms

\footnotetext{
${ }^{12}$ Notice that in our model there is a homogeneous labor market and the real wage is the same in all firms.
} 
is now larger in absolute terms and also in relation to the group of less efficient ones. It must be noted that the result of the simulation depicted in figure 2.b does not exactly correspond with the empirical evidence reported in Fact 3. What the real data tell is that the TFP gap between the firms at the technological frontier and the rest has widened in recent years. In fact, this occurs in our model since some firms that were previously in the technology group $A^{S}$ have now moved upwards with a higher TFP. Firms that were already in the upper technology group $\left(A^{L}\right)$ for low levels of the elasticity of substitution do not move upwards, since we are restricting ourselves to two categories. In a model with endogenous growth, arguably, these firms would also be interested in investing in better technologies, thus pushing the technology frontier up. Similarly, an increase in the cost of entry reduces the number of entrants to the group of smaller firms and thus increases the relative proportion of more efficient ones (see Figure 2.c).

Figure 3: Fact 4 - Response of markups and the source of increase in market share

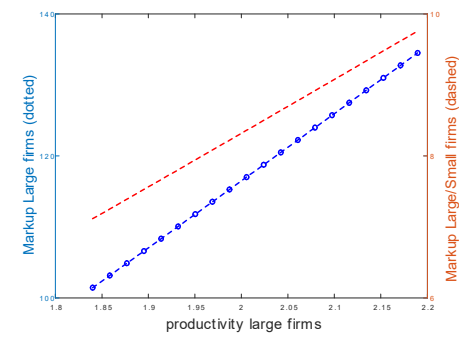

(a) Productivity large firms

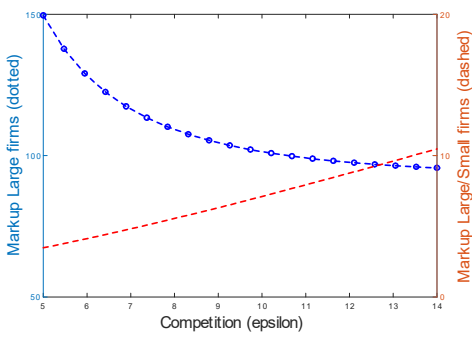

(b) Competition $(\varepsilon)$

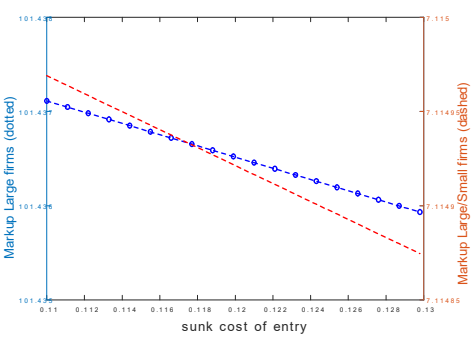

(c) Cost of entry

Fact 4. Markup increase. The expression (10) helps us understand the effect of steady state changes in the markup. The increase in $A^{L}$ raises the market share of large firms and hence their markup (see Figure 3a). The increase in the intensity of competition $(\varepsilon)$ depresses the markup of all firms regardless of their productivity (downward sloping blue line in Figure 3b), but this effect is stronger for small firms whose market share falls, pushing their markup further down. More efficient firms gain market share by taking advantage of their technological superiority to reduce prices and, hence, their markup falls by less than that of small less efficient firms (upward sloping red line in Figure $3 \mathrm{~b}) .{ }^{13}$

Figure 4: Fact 5 - Reduction in firm dynamics and entry

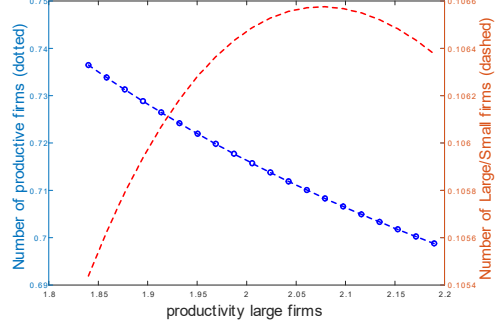

(a) Productivity large firms

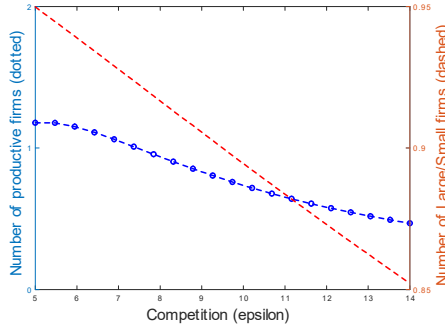

(b) Competition $(\varepsilon)$

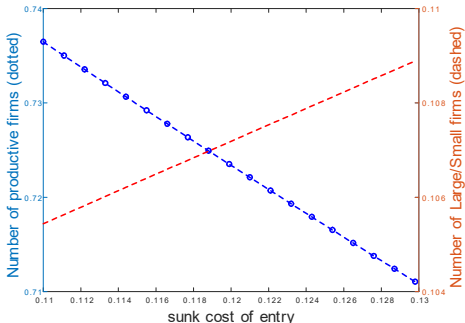

(c) Cost of entry

\footnotetext{
${ }^{13}$ Syverson $(2018,2019)$ shows that the diverging response of market shares and markups in response to an increase in the elasticity of substitution occurs in models in which some firms have some technological advantage over the rest in the market.
} 
Fact 5: Reduction in firm dynamics and firm entry. Figure 4 depicts several scenarios featuring a rise in market concentration. Firm entry falls, in all of cases, although for different reasons. The rise in the entry costs discourages entry for obvious reasons (Figure 4 panel c). If the rise in concentration is caused by an improvement in the technology of more efficient firms then their competitive advantage rises vis a vis the smaller companies which again reduces the markup of the latter (Figure 4 panel a). Potential entrants are small and will most likely remain so, unless they enjoy a sequence of positive shocks that would make them candidates to move up in the efficiency ladder. To the extent that the probability of remaining small for longer gets higher, the incentives for entering the market weaken and, as a result, the large to small firms ratio increases. At some point, though, this ratio bends down as the potential high markups of the top technology firms actually encourages entry again.

When there is an intensification in competition (rising $\varepsilon$ as in Figure 4 panel b) then the across the board reduction in the markup has a similar discouraging incidence on entry. In this case though, the number of large firms falls relative to the small ones. The fall in the markup undermines the incentive to incur in the costs of technological upgrading and reduces the relative number of high-technology firms. This channel operating through enhanced competition is the one that affects entry more strongly, displaying significant effects even as we consider small changes in $\varepsilon$.

Figure 5: Fact 6 - A reduction in investment rate (i/y)

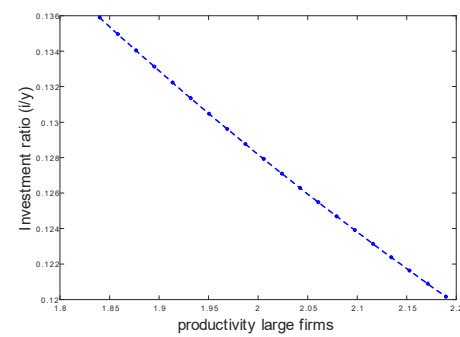

(a) Productivity large firms

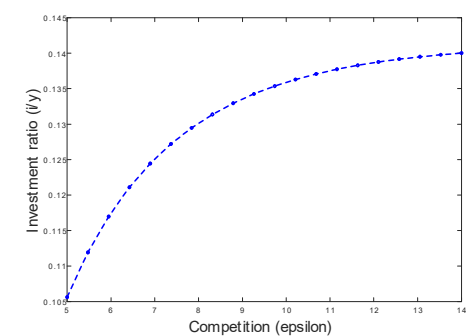

(b) Competition $(\varepsilon)$

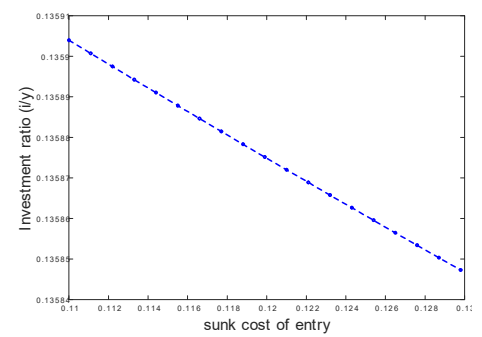

(c) Cost of entry

Fact 6: Sustained reduction in the aggregate investment rate. The response of the investment rate in the model depends on the cause of the rise in market concentration (see Figure 5). If the latter is driven by either technological improvements or an increase in entry costs then the aggregate investment rate declines slightly (Figure 5 panels a and c). In the first case, firms optimally chose to upgrade their technology rather than investing in productive capital, as in the margin it gives them a stronger advantage in terms of efficiency to reduce costs and gain market share. The incentive to invest in more efficient technologies still exists as competition increases (Figure 5 panel b) but it is weaker in this case. Thus, firms face the increase in demand by rising the use of productive factors. When varieties become so close substitutes that even small differences in efficiency matter most 
(very large $\varepsilon$ ), the incentive to upscale the technology kicks in and the investment rate stabilizes.

Figure 6: Fact 7 - Increase in profit share and reduction in capital share (rk/y)

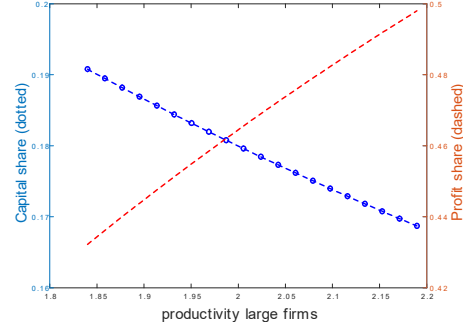

(a) Productivity large firms

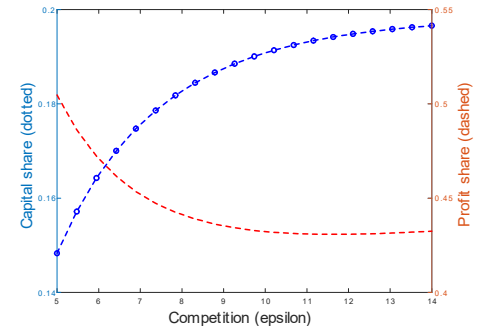

(b) Competition $(\varepsilon)$

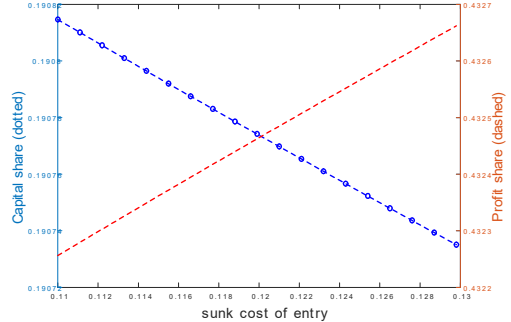

(c) Cost of entry

Fact 7: Declining capital share and rising participation of profits in total income. In all three panels of Figure 6, the profit rate and the capital share move in opposite directions, as observed in the data (See Barkai, 2019, among others). The capital share basically follows the same pattern as the investment rate discussed above. On the other hand, more efficient technologies and higher entry costs both push the profits of incumbent firms up, whereas the intensification of competition puts pressure on the markups reducing the profit share too.

Fact 8 refers to the response of output to transitory technology shocks and will be discussed in the next section

\section{$5 \quad$ Market shares and inflation}

The empirical facts reviewed in section 2 draw a clear picture of an increase in polarization generated by innovations and new business models in most industries. This is particularly clear in the U.S. for which there is more abundant evidence, but also in other OECD economies. This is best reflected in the increase in the market share of top firms in technologically advanced economies. In this section we discuss the short run dynamics of the model to show how this increase in market share by a few firms dampens their price adjustments in the face of shocks to the marginal cost, thus weakening the movements of the aggregate inflation rate.

In a world of competitive Bertrand pricing, more efficient firms, that also display larger market shares, will partially absorb shocks to their marginal cost, thus moderating the response of their markups. Also, these firms carry a large weight in the aggregate CPI. Thus, regardless of its causes, a rise in market concentration affects the Phillips curve. We now investigate the effect of firm heterogeneity on the response of the inflation rate to different shocks. We show that the long run process of firm polarization observed over the last decades causes, according to the logic of the model, a flattening of the Phillips Curve. 


\subsection{The Phillips curve and the dynamics of market power}

Key to understanding the differences of our setup with respect to the standard New Keynesian one (with homogeneous firms and Dixit-Stiglitz monopolistic competition) is the specification of the Phillips curve in both settings. In the model of this paper, the dynamics of inflation are driven by price stickiness that occurs at the intermediate retailers (IR) level. Log linearizing the pricing block of the model, i.e. equations (7), (8), (9), (11), and after some algebra, the dynamics of inflation of firms in the technology class $s$ can be represented as,

$$
\begin{aligned}
\left(\widehat{\Pi}_{t}^{s}-\chi_{s} \widehat{\Pi}_{t-1}^{s}\right)= & \frac{\left(1-\theta_{p}^{s}\right)\left(1-\beta \theta_{p}^{s}\right)}{\theta_{p}^{s}} \widehat{m c}_{t}^{s}+\beta \mathbb{E}_{t}\left(\widehat{\Pi}_{t+1}^{s}-\chi_{s} \widehat{\Pi}_{t}^{s}\right) \\
& +\frac{1-\theta_{p}^{s}}{\theta_{p}^{s}}\left(\widehat{\mu}_{t}^{d s}-\beta \theta_{p}^{s} \mathbb{E}_{t} \widehat{\mu}_{t+1}^{d s}\right)+\widetilde{f}\left(\Delta \widehat{\vec{p}}_{t}^{s}\right) \\
\text { where } \widetilde{f}\left(\Delta \widehat{\vec{p}}_{t}^{s}\right)= & \left(\frac{\left(\theta_{p}^{s} \beta-1\right)\left(1-\theta_{p}^{s}\right)}{\theta_{p}^{s}}\right) \widehat{\widetilde{p}}_{t}^{s} .
\end{aligned}
$$

Aside from the term $\tilde{f}\left(\Delta \widehat{\widetilde{p}}_{t}\right)$ that we describe below, the most relevant new component in this representation of the Phillips curve, as compared to the one in the standard New Keynesian model, is the term in the current and expected desired markup $\left(\widehat{\mu}_{t}^{d s}-\beta \theta_{p}^{s} \mathbb{E}_{t} \widehat{\mu}_{t+1}^{d s}\right)$. As a first approximation, its role is equivalent to the markup shocks that are often exogenously introduced in the Phillips curve to generate cost push shocks to inflation in a way that removes the divine coincidence (Blanchard and Galí, 2007; International Monetary Fund, 2019a). However, the crucial difference is that desired markups here enter endogenously in the equation and they themselves respond to changes in inflation. In fact, making use of the equations (10), (5) and (11) we can show that,

$$
\begin{aligned}
\widehat{\mu}_{t}^{d s}=\frac{1}{1+\eta_{p}^{s *}} \widehat{\eta}_{p t}^{s *} & =\frac{s^{s *}}{\left(1-s^{s *}\right)\left(\varepsilon\left(1-s^{s *}\right)-1\right)} \widehat{s}_{t}^{s *}, \\
\widehat{s}_{t}^{s *} & =-(\varepsilon-1) \widehat{\Pi}_{t}^{s *}, \\
\widehat{\Pi}_{t}^{s *} & =\frac{\theta_{p}^{s}}{1-\theta_{p}^{s}} \widehat{\Pi}_{t}^{s}+\widehat{\widetilde{p}}_{t}^{s} .
\end{aligned}
$$

Expression (17) confirms that changes in the desired markup are positively related to changes in the market share, implying that the markup that firms are able to charge on expected future marginal costs is increasing in their market power. ${ }^{14}$ As

\footnotetext{
${ }^{14}$ We impose the condition $\varepsilon\left(1-s^{s *}\right)>1$, which is equivalent to the condition $\varepsilon>1$ in a monopolistic competition model with no strategic pricing (so that the firm's market share would not affect its pricing) or one in which firms are homogenous in TFP and size (that would imply that $s^{s *}$ is arbitrarily small).
} 
expected, the market share diminishes when firms in the $s$ technological category rise their relative price, as reflected by (18). And, finally, the connection between relative prices and inflation in the $s$ category is captured by (19). As inflation increases in that category (e.g. due to shocks to the marginal cost) so does the optimal price of firms relative to the aggregate price. Combining all these elements, the mechanism linking heterogeneity and Bertrand competition becomes clear. Positive shocks to the marginal cost in a given technological class $s$ increase the inflation rate through the usual Calvo lottery channel, but this ends up eroding market power of firms in that category, which leads firms to charge a lower markup on their expected marginal costs, thus moderating the inflation rise. (A symmetric response occurs following negative shocks to marginal costs.)

These effects can be better viewed in a more compact form by plugging (17), (18) and (19) into (16), so that the dynamics of inflation in the $s$ technological class can be expressed as,

$$
\begin{aligned}
\left(\widehat{\Pi}_{t}^{s}-\chi_{s} \widehat{\Pi}_{t-1}^{s}\right) & =\underbrace{\left(\frac{1+\theta_{p}^{s} \xi_{N}^{s}}{1+\xi_{N}^{s}}\right)}_{\text {Heterogeneity effect }} \beta \mathbb{E}_{t}\left(\widehat{\Pi}_{t+1}^{s}-\chi_{s} \widehat{\Pi}_{t}^{s}\right) \\
& +\overbrace{\left(\frac{1}{1+\xi_{N}^{s}}\right)}^{\left(1-\theta_{p}^{s}\right)\left(1-\beta \theta_{p}^{s}\right)} \frac{\left(\widehat{m c}_{t}^{s}-\widehat{\bar{a}}_{t}^{s}\right)+f\left(\widetilde{\Delta} \widehat{\vec{p}}_{t}^{s}\right),}{\theta_{p}^{s}},
\end{aligned}
$$

where

$$
\begin{aligned}
& \xi_{N}^{s}=\frac{(\varepsilon-1) s^{s *}}{\left(1-s^{s *}\right)\left(\varepsilon\left(1-s^{s *}\right)-1\right)}>0 ;\left\{\frac{\partial \xi_{N}^{s}}{\partial \varepsilon}\right\}_{\bar{s}^{R *}}<0, \frac{\partial \xi_{N}^{s}}{\partial s^{s *}}>0, \\
& \widehat{\bar{a}}_{t}^{s}=\rho_{N}^{s+1} \widehat{N}_{t-1}^{s+1}+\rho_{N}^{s} \widehat{N}_{t-1}^{s}+\rho_{N}^{s-1} \widehat{N}_{t-1}^{s-1}+\rho_{a}^{s} \widehat{a}_{t}^{s}+\rho_{a}^{s-1} \widehat{a}_{t}^{s-1} \\
& f\left(\Delta \widehat{\widetilde{p}}_{t}^{s}\right)=-\frac{\left(1-\theta_{p}^{s} \beta+\xi_{N}^{s}\right)\left(1-\theta_{p}^{s}\right)}{\theta_{p}^{s}\left(1+\xi_{N}^{s}\right)} \widehat{\widetilde{p}}_{t}+\frac{\left(1-\theta_{p}^{s}\right) \xi_{N}^{s}}{\theta_{p}^{s}\left(1+\xi_{N}^{s}\right)} \beta \theta_{p}^{s} \mathbb{E}_{t} \widehat{\vec{p}}_{t+1}^{s},
\end{aligned}
$$

and $\rho_{N}^{s}$ and $\rho_{a}^{s}$ are convolutions of structural parameters. The term $\widehat{\bar{a}}_{t}^{s}$ captures changes in the composition of average productivity shocks of firms of type $s$ as well as changes in the number of firms in this technology group due to upgrading and downgrading to and from adjacent classes. Changes in this term are small at the business cycle frequency and so is their impact on inflation rates. Also, due to heterogeneity in productivity across firms, a term representing the impact of the change in relative prices, $f\left(\Delta \widehat{\widetilde{p}}_{t}\right)$, shows up. The quantitative relevance of this term on the dynamics of inflation is also second order.

According to (20), inflation dynamics in our model can be understood as determined, as in the standard New Keynesian case, solely by the dynamics of marginal 
costs and expected inflation, but now their coefficients are pre-multiplied by (a function) of the parameter $\xi_{N}^{s}$, which represents the heterogeneity effect. The value of $\xi_{N}^{s}$ depends entirely on the elasticity of substitution among varieties and on the steady state market share of each type of firms which in turn depends on the optimal relative price, $\Pi^{s *}$;see (6). In particular, the larger is the market share of firms of type $s$, the stronger the heterogeneity effect and the smaller the response of inflation to changes in the marginal cost.

The intuition behind this result can be gained again by looking at (17), that shows how the impact of changes in the market share on the desired markup is increasing in the steady state market share itself. Firms with less efficient technologies will charge a price above the market average, i.e. a relative price above one $\left(\Pi^{s *}>1\right)$; because of this, their market share $\left(s_{t}^{s}=\left(N N^{R}\left(\Pi^{s *}\right)^{\varepsilon-1}\right)^{-1} \Rightarrow 0\right)$ will tend to zero thus making the impact of further changes in the market share on their desired markup negligible. More efficient firms charge a price below the market average $\left(\Pi^{s *}<1\right)$ and will achieve a significant market share as time goes by, implying that the impact of variations in their market share on the desired markup are significant. Thus the model prediction in this respect is consistent with the recent results obtained by Amiti, Itskhoki, and Konings (2019), who find that strategic pricing is irrelevant for less efficient firms with negligible market shares, whereas it can be of first order importance for the more technologically advanced ones with substantial market shares.

Both firm heterogeneity and Bertrand competition are jointly necessary for the heterogeneity effect to be first order. If there is no strategic price competition, then $\frac{\partial p}{\partial p^{s *}} \frac{p^{s *}}{p}=0$, and the desired markup coincides with the standard case, $\mu^{d}=\frac{\varepsilon}{\varepsilon-1}$ and $\xi_{N}^{s}=0$. In this case the expression in (20) boils down to the standard NKPC. In other words, if there is no strategic pricing, the presence of firms with different technologies is basically irrelevant as far as the dynamics of aggregate inflation is concerned, since all intermediate retailers would perceive their desired markup as constant and unresponsive to market shares and pricing. On the other hand, even in the presence of strategic pricing, if firms are homogeneous (equally productive and hence with a relative price equal to 1 ) the market share of intermediate retailers would be constant and proportionally inverse to the number of firms; thus for sufficiently large $N N^{R}$, again $\eta_{p}^{s *}$ would get arbitrarily close to $-\varepsilon$, making $\xi_{N}^{s}$ very small with a negligible impact on inflation dynamics. ${ }^{15}$

Firm heterogeneity and strategic pricing together reduce the magnitude of the coefficients of the drivers of inflation that appear in the standard NKPC, dampening the response of the inflation rate to current and expected future marginal costs.

\footnotetext{
${ }^{15}$ If the number of firms $N N^{R}$ is sufficiently small so that the entry and exit of firms changes significantly the market share of each of them, we would obtain a moderating effect on inflation qualitatively similar to the heterogeneity effect described here. This mechanism is present in the model developed by Etro and Rossi (2015).
} 
This effect carries over to the aggregate inflation rate. Using equation (2), aggregate inflation can be expressed as the weighted average of the inflation rates of each firmsize, where the weights are the steady state market shares of intermediate retailers $\left(s^{s *}=\frac{\left(\Pi^{s *}\right)^{1-\varepsilon}}{N N^{R}}\right)$ so that $\widehat{\Pi}_{t}=\sum_{s=1}^{N} s^{s *} \widehat{\Pi}_{t}^{s}$ and we can write the aggregate NKPC as

$$
\left(\widehat{\Pi}_{t^{-}} \sum_{s=1}^{N}\left(\Pi^{s *}\right)^{1-\varepsilon} \chi_{s} \widehat{\Pi}_{t-1}^{s}\right)=\left[\begin{array}{c}
\sum_{s=1}^{N} s^{s *}\left(\frac{1+\theta_{p}^{s} \xi_{N}^{s}}{1+\xi_{N}^{s}}\right) \beta \mathbb{E}_{t}\left(\widehat{\Pi}_{t+1^{-}}^{s} \chi_{s} \widehat{\Pi}_{t}^{s}\right) \\
+\sum_{s=1}^{N} s^{s *}\left(\frac{1}{1+\xi_{N}^{s}}\right) \frac{\left(1-\theta_{p}^{s}\right)\left(1-\beta \theta_{p}^{s}\right)}{\theta_{p}^{s}}\left(\widehat{m c}_{t}^{s}-\widehat{\bar{a}}_{t}^{s}\right)
\end{array}\right]
$$

Therefore, as shown in (21), aggregate inflation dynamics are strongly influenced by the pricing behavior of large firms, which in turn react less to changes in their marginal costs. Hence, as market share polarization increases, the aggregate Phillips curve gets flatter.

As in Etro and Rossi (2015), the assumption of Bertrand pricing gives a role to the elasticity of substitution between varieties $(\varepsilon)$ as a determinant of the slope of the Phillips curve. An increase in sustitutability among varieties flattens the Phillips curve out, which is consistent with the extended intuition that in more competitive environments (higher $\varepsilon$ ) inflation is less responsive to shocks. Nonetheless, unlike in their model, now the effect of this parameter is not straightforward since it affects the response of inflation in several different ways.

Specifically, in our model, there are three channels through which $\varepsilon$ affects pricing. Two of them are captured by the negative sign of $\frac{\partial \xi_{N}^{s}}{\partial \varepsilon}$ keeping $\bar{s}^{R s *}$ constant $\left(\left\{\frac{\partial \xi_{N}^{s}}{\partial \varepsilon}\right\}_{\bar{s}^{R s *}}<0\right)$. According to this sign, an increase in the elasticity of substitution would reduce the heterogeneity effect, making the Phillips curve steeper. This is the net result of two opposite effects. On the one hand, there is a pure competition effect captured by (18) so that an increase in $\varepsilon$ strengthens the response of the market share to changes in the relative price of firms as it should be expected as competition intensifies. But on the other hand, in a more competitive market, the response of the markup to the market share is smaller, as reflected by (17). Since the second effect dominates the former, it becomes apparent that stronger competition weakens the heterogeneity effect, and hence augments the response of inflation. In fact there is a third channel that is not captured by the previous derivative term since, as shown previously, in a world of technological heterogeneity across firms, an increase in the elasticity of substitution among goods also increases the market share of the most efficient firms (see (5)) reinforcing the heterogeneity effect. The increase in $\varepsilon$ also reduces the market share of the less efficient firms, thus reducing their weight in the aggregate CPI inflation, which further contributes to reduce the slope of the aggregate Phillips curve. 


\subsection{Inflation and the market share: TFP shocks}

Next we conduct a series of simulations to analyze how changes in the market structure of an economy that affect the distribution of firms in terms of their technology affect the response of inflation to a common (neutral) technological shock. We show the responses of inflation to this shock under different structural scenarios, characterized by differences in the dispersion of TFP across firms and in the elasticity of substitution between varieties. Again, we do not look at other determinants of the distribution of firms, like entry costs, upgrading and downgrading sunk costs, or firms' death rates that, as we discussed in the previous section, have a negligible impact on market shares and hence do not have a first order effect on the slope of the Phillips curve. ${ }^{16}$

Figure 7.a. Impulse responses of inflation under different productivity scenarios $20 \%$ increase in all firms' productivity $(A)$
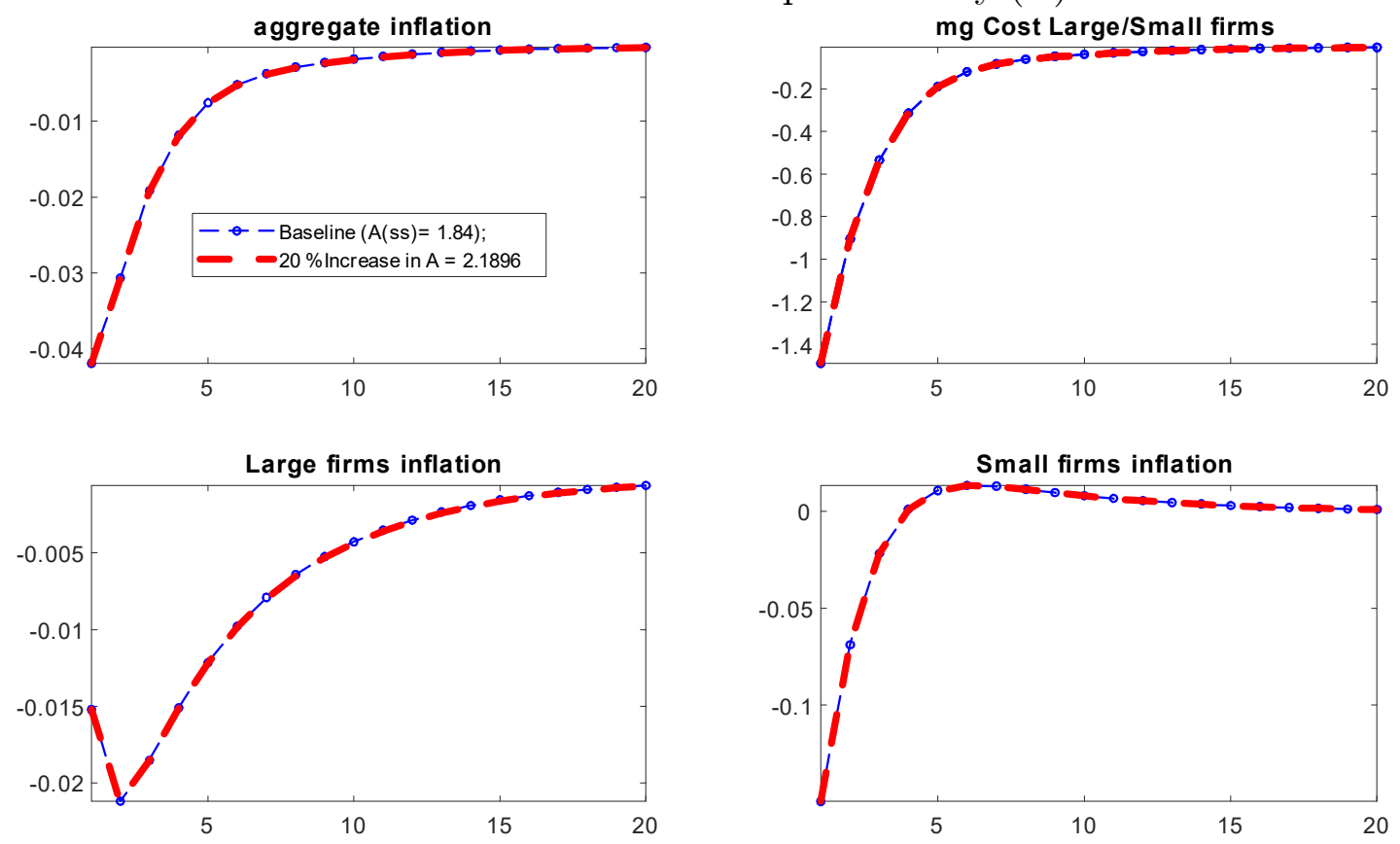

Figure 7 depicts the differences in the responses of aggregate and sectorial inflation to neutral TFP shock in alternative steady state $\left\{A^{S}, A^{L}\right\}$ scenarios. In Panel a), we compare the impulse responses in the benchmark economy (blue dotted lines) with one in which both $A^{S}$ and $A^{L}$ increase proportionally, leaving $\left\{A^{S}-A^{L}\right\}$ unchanged (red dashed lines). Given this proportional change, that does not affect the market share of firms, there is no difference in the dynamics of inflation (neither in the aggregate rate nor in the inflation rate of each class of firms) across the two steady state scenarios. Nevertheless, this exercise confirms that, consistent with the

\footnotetext{
${ }^{16}$ In particular, in the case of entry costs, the fact that entry in the market is calibrated to be (realistically) small and that entrants are small firms explains that the impact of this change is of lesser importance, as compared with the other causes of increased market concentration. The figures corresponding to these cases are available upon request.
} 
Figure 7.b. Impulse responses of inflation under different productivity scenarios $20 \%$ increase in Large firms' productivity $\left(A^{L}\right)$
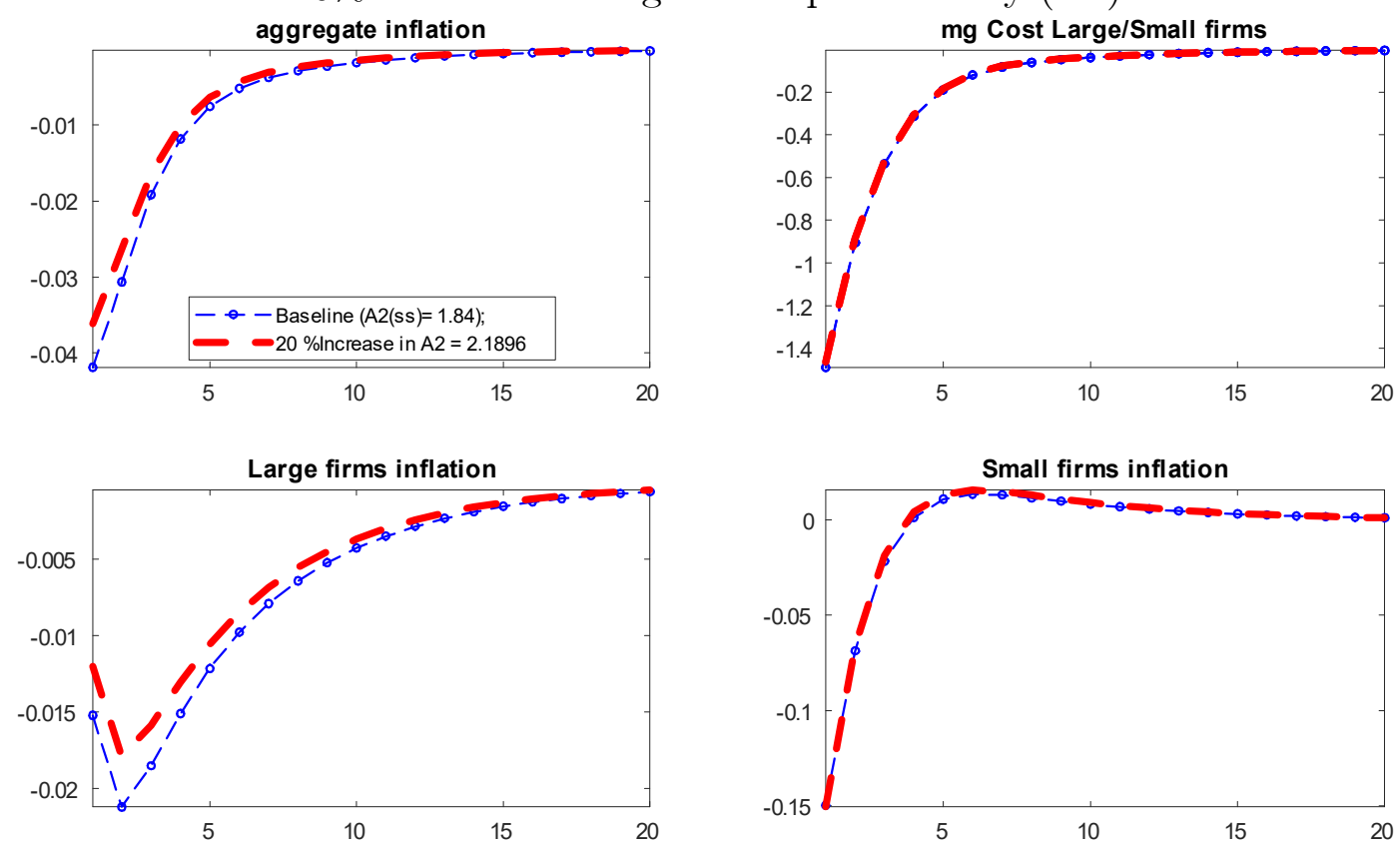

Figure 7.c. Impulse responses of inflation under different productivity scenarios $20 \%$ increase in Small firms' productivity $\left(A^{S}\right)$
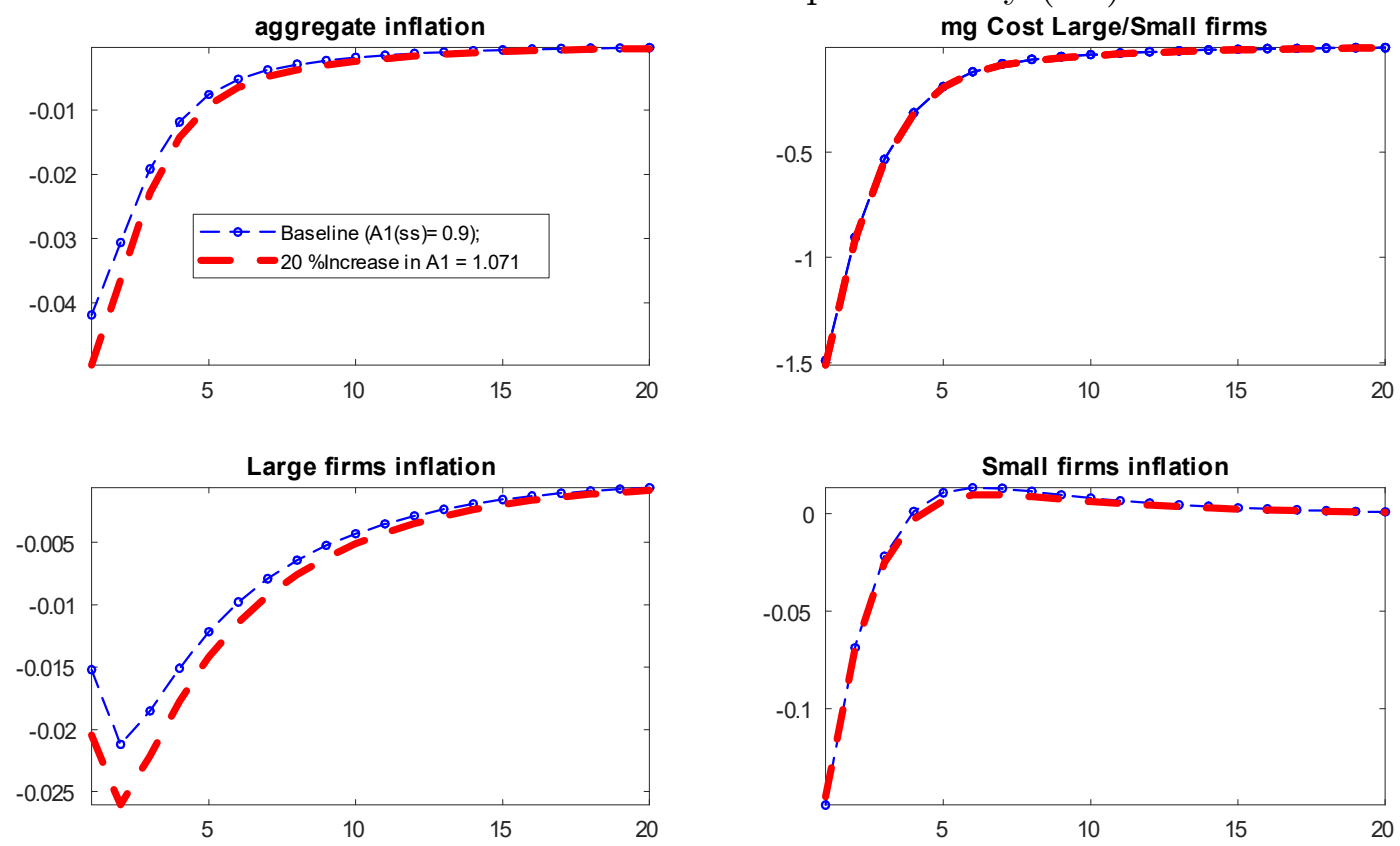

theoretical discussion above, the inflation rate of large firms reacts much less than that of small firms. Furthermore, the ratio of the inflation response to the change in the marginal cost in each TFP category (a rough approximation to the slope of the Phillips curve) is much smaller for large firms with a high market share. Less efficient firms' inflation responds on impact in scale of 0.1 with respect to the shock to their marginal cost, whereas firms with a larger market share respond much less (0.01, see table 5$)$ 
In Panel b we compare this responses in the benchmark scenario described in the calibration $\left(A^{S}=0,93, A^{L}=1,84\right)$ against those in an alternative one in which the productivity of the more efficient firms is 20 percent higher $\left(A^{L}=2,19\right)$. As was shown in the previous section, this shock contributes to polarize the market, widening the gap in market shares between large and small firms. Hence, this shock exacerbates the difference in the response of inflation across the two types of firms. As the productivity of more efficient firms $\left(A^{L}\right)$ has increased, their market share goes up and thus they respond even less to the shock to marginal costs, which is reflected in a less volatile aggregate inflation rate. In fact, these firms' inflation now responds on impact a 20 per cent less with respect to the shock to their marginal cost, whereas the inflation of less efficient ones does not change their response (see table 5). Moreover, inflation volatility goes down by 26 per cent, driven by the drop in the volatility of large firms' inflation (see table 6 below).${ }^{17}$

The opposite result is obtained if $A^{S}$, rather than $A^{L}$ increases (Panel c). In this case, as the industrial structure becomes more homogenous and the market share of the largest firms fall, their inflation becomes more sensitive to their drivers and so does the aggregate inflation rate.

Table 5: Ratio of the impulse response of inflation to the one of marginal cost on impact

$\begin{array}{lccc} & \text { Large } & \text { Small } & \text { Large/Small } \\ \text { Baseline } & 0.010 & 0.100 & 0.10 \\ \text { 20\% increase in parameter: } & & & \\ \text { Productivity of ALL firms }(A) & 0.010 & 0.101 & 0.10 \\ \text { Productivity of LARGE firms }\left(A^{L}\right) & 0.008 & 0.103 & 0.08 \\ \text { Productivity of SMALL firms }\left(A^{S}\right) & 0.014 & 0.096 & 0.14 \\ \text { Elasticity of demand }(\varepsilon) & 0.008 & 0.104 & 0.08\end{array}$

We saw in the previous section that the change in the elasticity of substitution $(\varepsilon)$ is one possible, and powerful, explanation of the market share increase by the most technologically advanced firms. The theoretical discussion of the determinants of the Phillips curve revealed that changes in $\varepsilon$ had an ambiguous effect on the slope of the Phillips curve since it operates through several, potentially diverging, channels. The overall effect of a permanent change in $\varepsilon$ is nonetheless unambiguous according to the impulse responses in face of a positive neutral TFP shock in Figure 8. We also find that in a more competitive environment (driven by an increase of $\varepsilon$ from 10 up to 12 , that implies a reduction in the average markup of firms by about 4 percentage

\footnotetext{
${ }^{17}$ The qualitative effect is clear, although the quantitative change in the response of inflation is not large. Nonetheless, notice that the increase in $A^{L}$ by 20 percent only induces a moderate increase in market share of large firms of 2.4 percentage points.
} 
points) the inflation rate response diminishes. In particular, the model produces a drop in the ratio of the impact response of inflation relative to that of the marginal cost by the more technologically advanced firms of 20 per cent, in line with the result obtained under an increase of $A^{L}$ (Table 5).

Figure 8. Impulse responses of inflation under different structural scenarios
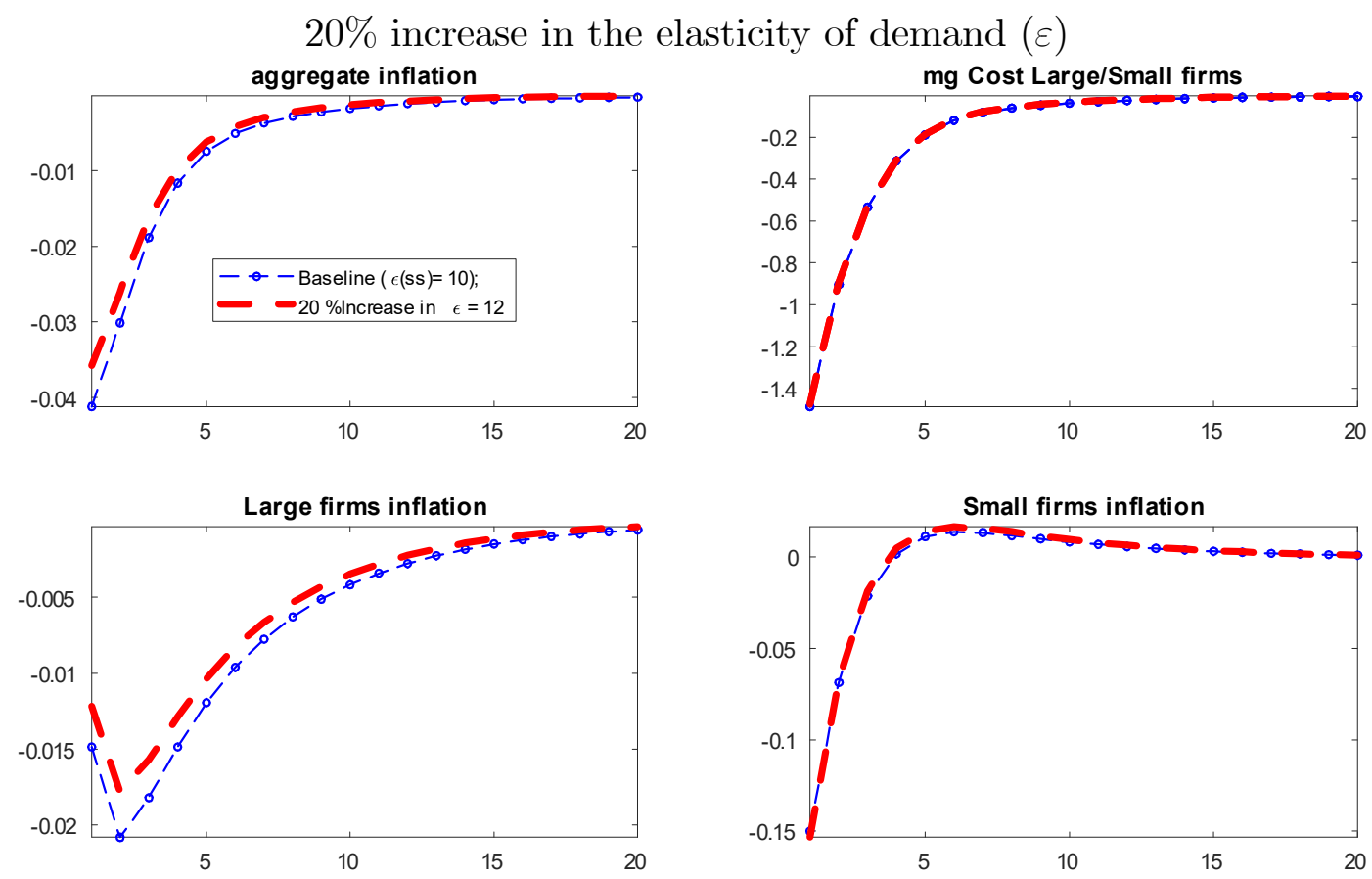

It is important to notice that this effect is not the usual competition effect that makes prices more sensitive to competition, as in standard models. As discussed above, the standard competition effect is indeed present through equation (18) but it is dominated by the diminished impact of market shares on desired markups (equation (17)), making the heterogeneity effect weaker $\left(\left\{\frac{\partial \xi_{N}^{s}}{\partial \varepsilon}\right\}_{\bar{s}^{R s *}}\right)$. The critical mechanism that overturns this diminishing impact on the heterogeneity effect goes against the conventional intuition. In particular, it relies on the fact that higher sustitutability among varieties (that can be interpreted as a pro-competition shock) actually pushes the market share of technological advanced firms up (see (5)) and, hence, makes their market share more sensitive to changes in their own price, providing incentives for this firms to moderate their changes in prices.

\subsection{Other shocks}

The moderating effect on the inflation response market polarization also occurs in response to other types of shocks. Figures 9 and 10 depict the responses of inflation to three alternative shocks hitting monetary policy, preferences and labor supply. In both figures we compare two alternative firm polarization scenarios driven either by changes in $A^{L}$ (Figure 9) or in $\varepsilon$ (Figure 10). 
Regardless of its cause behind higher polarization, the inflation response by large firms to all the shocks is, whether positive or negative, weaker than that of the smaller companies. Moreover, polarization in the market share of firms, whether caused by technology or competition exacerbates these differences between small and large firms with a decreasing response of inflation as the latter gain market share. Also the volatility of most macroeconomic variables, conditional on each of these shocks, falls with few exceptions (see Table 6).

Figure 9. $20 \%$ increase of large firms' productivity $\left(A^{L}\right)$
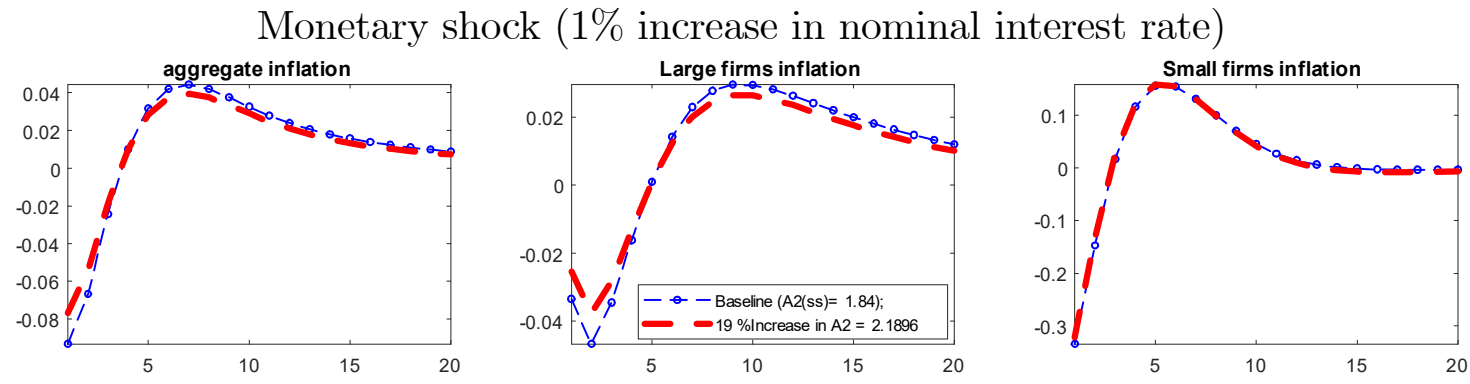

Preference shock
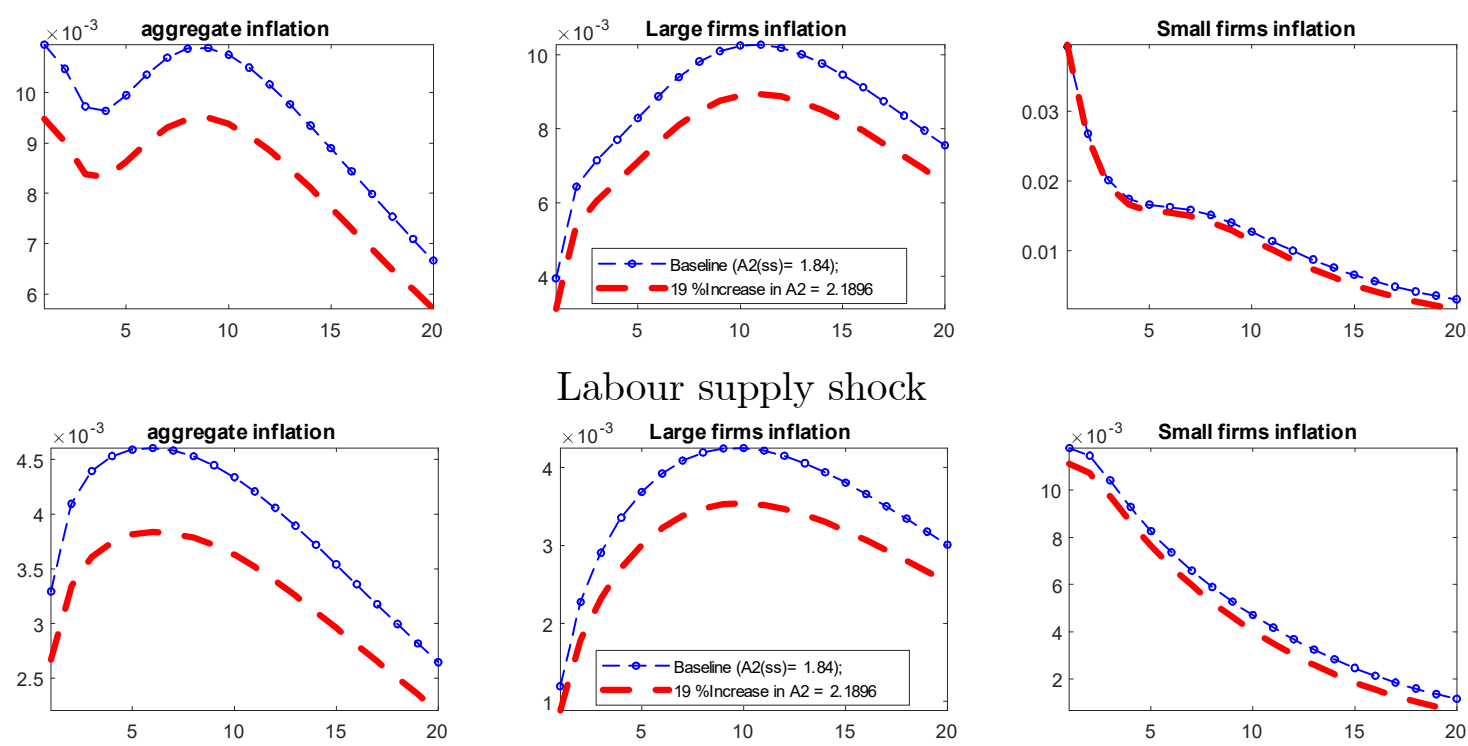

Labour supply shock
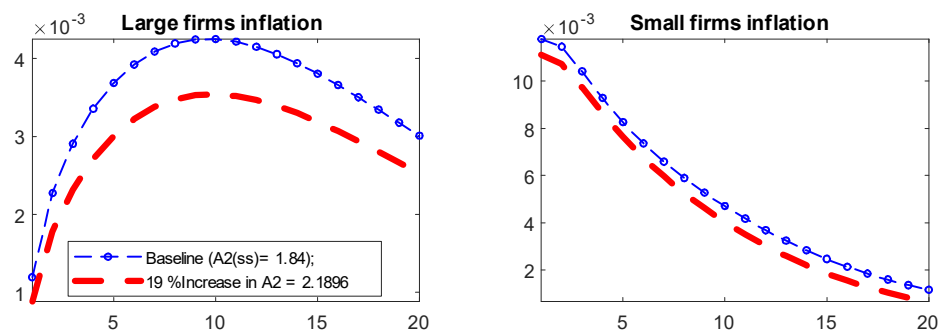

There is an additional result that deserves some attention here, despite not being related to the response of inflation. As Table 6 reveals, the response of output to a neutral technology shock and to a labor supply shock diminishes when firms become more polarized so that more technologically advanced firms increase their market shares. This is consistent with Fact $\mathbf{8}$ discussed in section 2. Independently of the reason for the increase in polarization, either an improvement in the top firms' technology or in the elasticity of demand, we observe a marked fall in output and employment volatility. A shock to the marginal cost (either a TFP or a wage shock) induces a countercyclical response in the markup that is more pronounced the larger the market share of the firm is. Thus, the negative impact on firms sales due to 
Figure 10. 20\% increase in the elasticity of demand $(\varepsilon)$

Monetary shock (1\% increase in nominal interest rate)
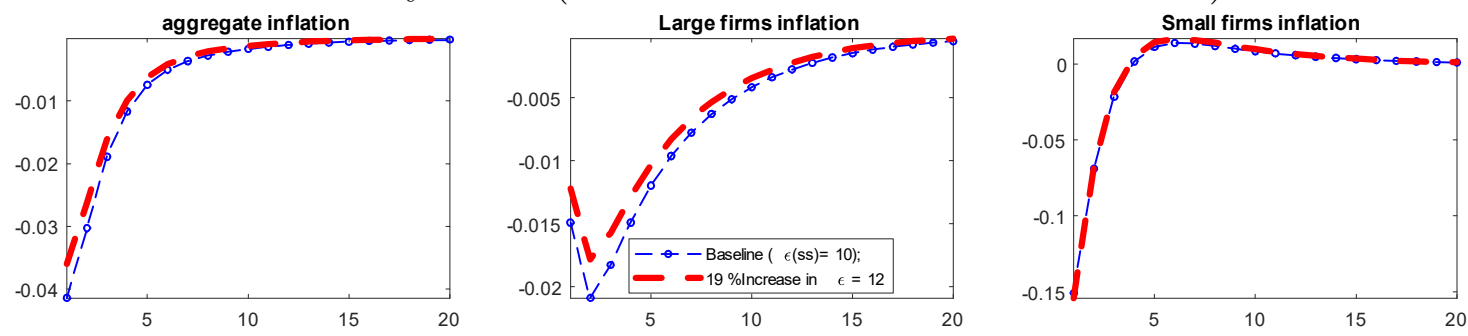

Preference shock
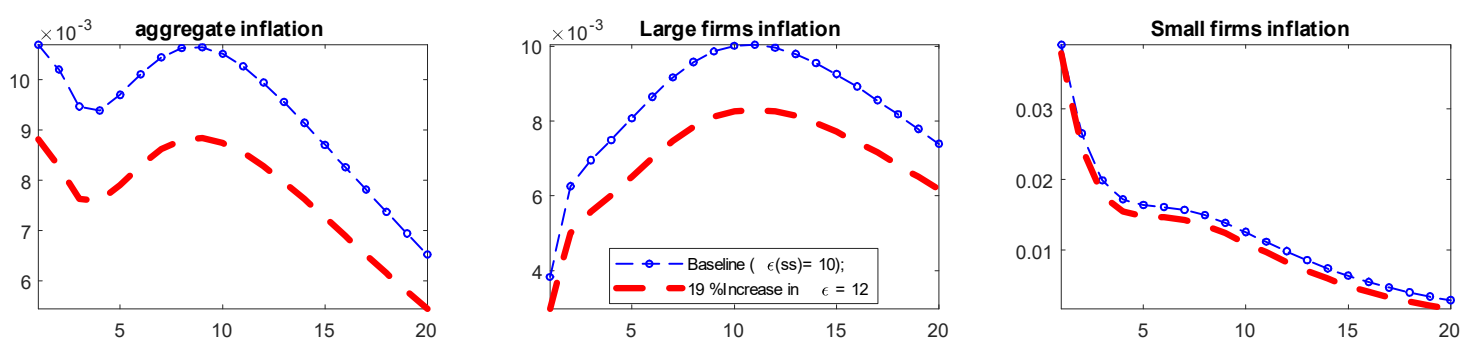

Labour supply shock
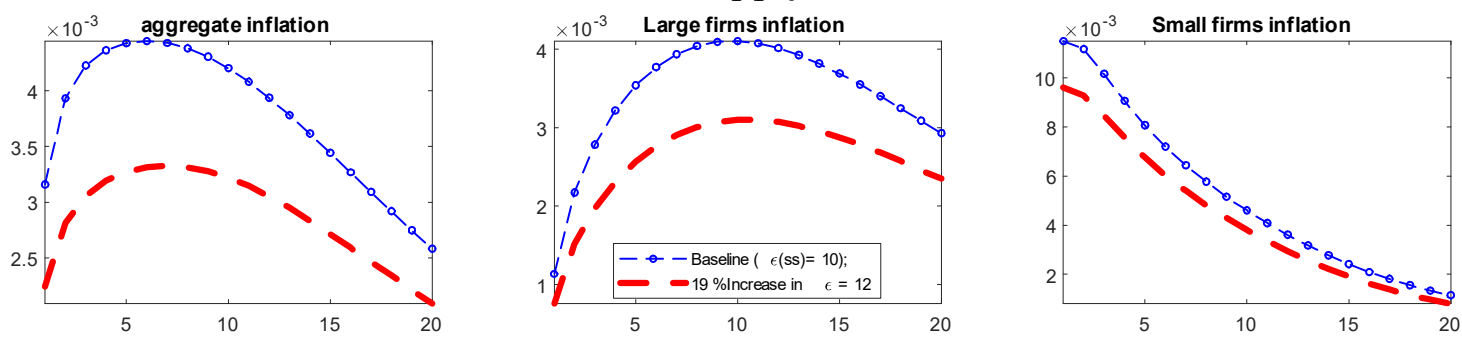

Table 6: Percentage change in the volatility of variables

$20 \%$ increase in large firms' productivity 2.19 vs 1.84

Neut. prod.

Mon Pref
$20 \%$ increase in the elasticity of demand $(\varepsilon) 12$ vs 10

\begin{tabular}{|c|c|c|c|c|c|c|c|c|}
\hline & $\begin{array}{l}\text { Neut. } \\
\text { prod. }\end{array}$ & Mon. & Pref. & $\begin{array}{l}\text { Lab. } \\
\text { sup. }\end{array}$ & $\begin{array}{l}\text { Neut. } \\
\text { prod. }\end{array}$ & Mon. & Pref. & $\begin{array}{l}\text { Lab. } \\
\text { sup. }\end{array}$ \\
\hline nflation & -26.2 & -27.6 & -25.3 & -30.9 & -25.3 & -23.7 & -31.6 & -40.7 \\
\hline Infl. Large firms & -28.4 & -27.7 & -25.6 & -31.0 & -27.3 & -24.3 & -31.6 & -40.3 \\
\hline Inf. Small firms & 0.4 & -4.4 & -7.9 & -16.3 & 4.1 & 4.0 & -15.4 & -30.8 \\
\hline Output & -29.7 & -6.5 & 9.5 & -40.2 & -25.9 & 1.6 & 2.4 & -51.7 \\
\hline Employment & -11.9 & -11.8 & -3.3 & 18.1 & -5.5 & 0.1 & -3.2 & -11.3 \\
\hline Nages & -15.1 & 9.3 & -10.9 & -1.7 & -1.6 & -14.8 & -27.4 & -18.6 \\
\hline
\end{tabular}

an adverse shock is smaller than under constant markups. As inflation increases by less, so does the real interest rate, which moderates the fall in demand. This finding is consistent with the "Great Moderation" of output observed in most developed economies since the early eighties (Stock and Watson, 2003). Yet the reason behind this phenomenon -increasing firm polarization- would differ from other explanations provided in the previous literature. 


\section{Conclusions}

The flattening of the Phillips curve that has taken place over the last twenty years poses a challenge for monetary authorities seeking to rationalize the muted response of inflation to changes in the economy's slack. The availability of large data sets containing firm level information on a number of relevant variables has uncovered a series of facts that speak of profound changes in the distribution of firms in many industries in terms of market share, productivity, employment, etc. These changes are increasingly attracting the attention of macroeconomists, to the extent that they might have had repercussion in the response of macroeconomic variables to exogenous shocks. In this paper we set up a model consistent with many of the features highlighted by the empirical industrial organization literature, to argue that these changes might well be behind the muted response of inflation to shocks to the marginal costs that has been observed lately.

In our model, the polarization of firms in terms of market share, productivity and, to a lesser extent, employment come as a result of different forces: technological superiority of some firms, increase in sustitutability among varieties or barriers of entry. In all cases, the rise in the market share of a few large firms has a moderating impact on inflation, both at the sector and at the aggregate level. Large firms tend to respond by less to shocks to their costs than smaller firms. As polarization increases, this moderating effects becomes amplified and reinforced at the aggregate level because of the increasing weight of large companies on total market sales and on aggregate inflation.

Key to this result is the presence of two features that are absent in the canonical New Keynesian model. First, we depart from the firm homogeneity paradigm and allow for heterogeneity in total factor productivity across firms. In our model, there is also entry and exit of firms. Although all entrants (endogenous decision) do so at the bottom of the TFP ladder, they may later eventually upgrade or downgrade their technology endogenously by incurring in some fixed costs. Since competition depends critically on cost advantages the price decision is of paramount importance. Our second important departure from the standard New Keynesian model is that we consider a competitive framework whereby firms take into account the reaction of their competitors when setting their own prices à la Bertrand.

These two features give rise to a modified Phillips curve whose slope is diminished by a factor that increases with the market share of firms in the market. Thus our model predicts that as market concentration around a few firms across industries increases, the response of aggregate inflation to changes in the marginal cost becomes more muted, consistent with the empirical evidence. 


\section{Appendix I: Households}

There is a continuum of households in our economy indexed by $j \in[0,1]$. Each household maximizes the following lifetime utility function, which is separable in per capita consumption, $c_{j t}$, and per capita hours worked, $l_{j t}$ (in terms of proportion of the day spent at work):

$$
\mathbb{E}_{0} \sum_{t=0}^{\infty} \beta^{t} d_{t}\left\{\frac{c_{j t}^{1-\sigma}}{1-\sigma}-\varphi_{t} \psi \frac{\left(l_{j t}\right)^{1+\vartheta}}{1+\vartheta}\right\}
$$

where $\beta$ is the discount factor and $\vartheta$ is the inverse of Frisch labor supply elasticity. $d_{t}$ is an intertemporal preference shock and $\varphi_{t}$ is a labor supply shock both with an $\operatorname{AR}(1)$ law of motion.

The number of operative firms is endogenous and we assume that firms can have different steady state levels of productivity, which naturally leads to different size classes. All prospective entrants are of the smallest size. After entry, firms may change size, but we only consider transitions to the nearest group size. Therefore, every period of surviving firms a fraction $\int_{a_{t+1}^{L s-1}}^{1} d i$ of firms of size $s-1$ become larger and a proportion $\left(\int_{0}^{a_{t+1}^{S s+1}} d i\right)$ of firms of size $s+1$ diminish in size. In addition, a fraction $\delta^{F s}$ of firms of each size (including entrant firms) stop producing. The dynamics of firms by class is,

$$
N_{t+1}^{s}=\left[\begin{array}{c}
\left(\int_{a_{t+1}^{L s-1}}^{1} d i\right)\left(1-\delta^{F s-1}\right) N_{t}^{s-1}+\left(\int_{0}^{a_{t+1}^{S s+1}} d i\right)\left(1-\delta^{F s+1}\right) N_{t}^{s+1} \\
+\left(\int_{a_{t+1}^{S s}}^{a_{t+1}^{L s}} d i\right)\left(1-\delta^{F s}\right) N_{t}^{s}
\end{array}\right]
$$

and the number of operating and dividend yielding firms $\left(N^{H}\right)$ evolves as,

$$
N_{t+1}^{H}=\sum_{s=1}^{N} N_{t+1}^{s}=\left(1-\delta^{F 0}\right) N_{t}^{0}+\sum_{s=1}^{N}\left(1-\delta^{F s}\right) N_{t}^{s}
$$

where we assume that death rates are exogenous, while entry and growth are endogenous.

There is a mutual fund of firms paying a dividend each period equal to the total nominal profit of all firms producing in that period, $p_{t} d_{t}^{F} N_{t}^{H}$, where $d_{t}^{F}=\frac{1}{N_{t}^{H}} \int_{0}^{N_{t}^{H}} d_{i, t}^{F} d i$ is the average real profit and $p_{t}$ the aggregate price level. During period $t$, each household buys $s h_{j t}$ shares in the fund of all the firms in the economy, since they do not know what firms will stop producing this period and will not pay dividends at $t+1$, or which ones will change size. The date $t$ price of a claim to the future profit stream of the mutual fund of $N_{t}$ firms is equal to the average nominal price of claims of future profits of firms, $p_{t} e_{t} N_{t}=p_{t} \sum_{s=1}^{N} e_{t}^{s} N_{t}^{s}$, where $e_{t}=\frac{1}{N_{t}^{H}} \int_{0}^{N_{t}^{H}} e_{i, t} d i$ is the average real value of producing firms. 
Therefore, households hold three types of assets: government bonds $b_{j t}$, which pay a nominal gross interest rate of $R_{t}$, physical capital $k_{j t}$, that earns a real rate of return of $r_{t}$, and shares in the mutual fund of firms $s h_{j t}^{s}$, where the superscript $s$ stands for the class of firms the mutual fund invests on. Then, the $j_{t h}$ household's per capita budget constraint is given by

$$
\begin{gathered}
c_{j t}+i_{j t}+\frac{b_{j t}}{p_{t}}+\sum_{s=0}^{N} e_{t}^{s} N_{t}^{s} s h_{j t}^{s}=T_{t}+w_{j t} l_{j t}+r_{t} k_{j t-1}+\sum_{s=0}^{N} d_{t}^{R F s}+R_{t-1} \frac{b_{j t-1}}{p_{t}} \\
+\sum_{s=0}^{N}\left[\begin{array}{c}
\int_{a_{t}^{L s}}^{a^{\max }}\left(\begin{array}{c}
\left.d_{i t}^{F s+1}-F_{t}^{s+1}-f_{t}^{L s+1}+e_{t}^{s+1}\right) d i \\
+\int_{a_{t}^{S s}}^{a^{L s}}\left(d_{i t}^{F s}-F_{t}^{s}+e_{t}^{s}\right) d i \\
+\int_{0}^{a_{t}^{S s}}\left(d_{i t}^{F s-1}-F_{t}^{s-1}-f_{t}^{S s-1}+e_{t}^{s-1}\right) d i
\end{array}\right]\left(1-\delta^{F s}\right) N_{t-1}^{s} s h_{j t-1}^{s}
\end{array}\right.
\end{gathered}
$$

while investment $i_{j t}$ induces a law of motion for capital of the household:

$$
\mathbb{E}_{t} k_{j t}=(1-\delta) k_{j t-1}+\mu_{t}\left(1-S\left[\frac{i_{j t}}{i_{j t-1}}\right]\right) i_{j t}
$$

$S[\cdot]$ is an adjustment cost function such that $S[1]=0, S^{\prime}[1]=0$, and $S^{\prime \prime}[\cdot]>0$ and $\mu_{t}$ is an $\operatorname{AR}(1)$ investment-specific technological shock. The value of $\mu_{t}$ is also the inverse of the relative price of new capital in consumption terms.

Households maximize over $c_{j t}, b_{j t}, k_{j t}, s h_{j t}^{s}, i_{j t}$ and $l_{j t}$. Since we assume complete markets and separable utility in labor, we consider a symmetric equilibrium where $c_{j t}=c_{t}, k_{j t}=k_{t}, i_{j t}=i_{t}, \lambda_{j t}=\lambda_{t}$ and $q_{j t}=q_{t}{ }^{18}$ The aggregate first order conditions associated to the consumer's problems are:

$$
\begin{gathered}
d_{t} c_{t}^{-\sigma}=\beta \mathbb{E}_{t}\left[d_{t+1} c_{t+1}^{-\sigma} \frac{R_{t}}{\Pi_{t+1}}\right] \\
d_{t} c_{j t}^{-\sigma} e_{t}^{s}=\beta \mathbb{E}_{t} d_{t+1} c_{j t+1}^{-\sigma}\left(1-\delta^{F s}\right)\left\{\begin{array}{c}
\int_{a_{t+1}^{L s}}^{a^{\max }}\left(d_{i t+1}^{F s+1}-F_{t+1}^{s+1}-f_{t}^{L s+1}+e_{t+1}^{s+1}\right) d i \\
+\int_{a_{t+1}^{S s}}^{a_{t+1}^{L s}}\left(d_{i t+1}^{F s}-F_{t+1}^{s}+e_{t+1}^{s}\right) d i \\
+\int_{0}^{a_{t+1}^{S s}}\left(d_{i t+1}^{F s-1}-F_{t+1}^{s-1}-f_{t}^{S s-1}+e_{t+1}^{s-1}\right) d i
\end{array}\right\} \text { for } s=0, \ldots, N \\
q_{t}=\beta \mathbb{E}_{t} \frac{d_{t+1} c_{t+1}^{-\sigma}}{d_{t} c_{t}^{-\sigma}}\left\{q_{t+1}(1-\delta)+r_{t+1}\right\} \\
1=q_{t} \mu_{t}\left(1-S\left[\frac{i_{t}}{i_{t-1}}\right]-S^{\prime}\left[\frac{i_{t}}{i_{t-1}}\right] \frac{i_{t}}{i_{t-1}}\right)+\beta \mathbb{E}_{t} q_{t+1} \frac{d_{t+1} c_{t+1}^{-\sigma}}{d_{t} c_{t}^{-\sigma} \mu_{t+1} S^{\prime}\left[\frac{i_{t+1}}{i_{t}}\right]\left(\frac{i_{t+1}}{i_{t}}\right)^{2}}
\end{gathered}
$$

\footnotetext{
${ }^{18}$ We define the (marginal) Tobin's $\mathrm{Q}$ as $q_{j t}=\frac{Q_{j t}}{\lambda_{j t}}$, (the ratio of the two Lagrangian multipliers, or more loosely the value of installed capital in terms of its replacement cost), where $\lambda_{j t}$ and $q_{j t}$ are the Lagrangian multipliers associated with the budget constraint and capital accumulation equations,
} 
The first-order conditions with respect to labor and wages are more involved (see Erceg, Henderson and Levin (2000)). We assume a continuum of monopolistically competitive households, each of which supplies a differentiated labor service to the production sector; that is, firms regard each household's labor services $l_{j t}$, as an imperfect substitute for the labor services of other households. It is convenient to assume that a representative competitive firm (or employment agency) hires the labor supplied by each household $j, l_{j t}$, and combines these labor hours in the same proportions as intermediate good producers would choose, using the following labor input production function,

$$
l_{t}^{d}=\left(\int_{0}^{1}\left(l_{j t}\right)^{\frac{\eta-1}{\eta}} d j\right)^{\frac{\eta}{\eta-1}}
$$

where $0 \leq \eta<\infty$ is the elasticity of substitution among different types of labor, $l_{t}^{d}$ is the total labor demand. Thus, the labour demand function for household's $j$ labor by all firms and aggregate wage are given by:

$$
\begin{aligned}
& l_{j t}=\left(\frac{w_{j t}}{w_{t}}\right)^{-\eta} l_{t}^{d} \quad \forall j \\
& w_{t}=\left(\int_{0}^{1} w_{j t}^{1-\eta} d j\right)^{\frac{1}{1-\eta}}
\end{aligned}
$$

Households set their wages following a Calvo lottery. In each period, a fraction $1-\theta_{w}$ of households can change their wages. All other households can only index their wages to either past inflation or steady state inflation, which is controlled by the parameter $\chi_{w} \in[0,1]$, where $\chi_{w}=0$ is only indexation to steady state inflation and $\chi_{w}=1$ is total indexation to past inflation. Thus, the relevant part of the Lagrangian for the household is:

$$
\begin{gathered}
\max _{w_{j t}} \mathbb{E}_{t} \sum_{\tau=0}^{\infty} \theta_{w}^{\tau} \beta^{\tau}\left\{-d_{t+\tau} \varphi_{t+\tau} \psi \frac{\left(l_{j t+\tau}^{s}\right)^{1+\vartheta}}{1+\vartheta}+\lambda_{j t+\tau} \prod_{s=1}^{\tau} \frac{\Pi^{1-\chi_{w}} \prod_{t+s-1}^{\chi_{w}}}{\Pi_{t+s}} w_{j t} l_{j t+\tau}\right\} \\
\text { s.t. } l_{j t+\tau}=\left(\prod_{s=1}^{\tau} \frac{\Pi^{1-\chi_{w} \Pi_{t+s-1}^{\chi_{w}}}}{\Pi_{t+s}} \frac{w_{j t}}{w_{t+\tau}}\right)^{-\eta} l_{t+\tau}^{d}
\end{gathered}
$$

All households that can optimize their wages in this period set the same wage $\left(w_{t}^{*}=\right.$ $w_{j t} \forall j$ that optimizes) because complete markets allow them to hedge the risk of the timing of wage change; hence, we can drop the $j t h$ from the choice of wages and $\lambda_{j t}$. The first-order condition of this problem is expressed recursively through the use of the auxiliary variable $f_{t}$ and substituting for $\lambda_{j t}=d_{t} c_{j t}^{-\sigma}$, to have

$$
f_{t}=\frac{\eta-1}{\eta}\left(w_{t}^{*}\right)^{1-\eta} d_{t} c_{j t}^{-\sigma} w_{t}^{\eta} l_{t}^{d}+\beta \theta_{w} \mathbb{E}_{t}\left(\frac{\Pi^{1-\chi_{w}} \Pi_{t}^{\chi_{w}}}{\Pi_{t+1}}\right)^{1-\eta}\left(\frac{w_{t+1}^{*}}{w_{t}^{*}}\right)^{\eta-1} f_{t+1}
$$


and

$$
f_{t}=d_{t} \varphi_{t} \psi\left(\frac{w_{t}^{*}}{w_{t}}\right)^{-\eta(1+\vartheta)}\left(l_{t}^{d}\right)^{1+\vartheta}+\beta \theta_{w} \mathbb{E}_{t}\left(\frac{\Pi^{1-\chi_{w}} \Pi_{t}^{\chi_{w}}}{\Pi_{t+1}}\right)^{-\eta(1+\vartheta)}\left(\frac{w_{t+1}^{*}}{w_{t}^{*}}\right)^{\eta(1+\vartheta)} f_{t+1}
$$

In a symmetric equilibrium and in every period, a fraction $1-\theta_{w}$ of households set $w_{t}^{*}$ as their wage, while the remaining fraction $\theta_{w}$ partially index their wage to either past or steady state inflation. Consequently, the real wage index is a geometric average of past real wage and the new optimal wage:

$$
w_{t}^{1-\eta}=\theta_{w}\left(\frac{\Pi^{1-\chi_{w}} \Pi_{t-1}^{\chi_{w}}}{\Pi_{t}}\right)^{1-\eta} w_{t-1}^{1-\eta}+\left(1-\theta_{w}\right) w_{t}^{* 1-\eta} .
$$

\section{Appendix II: Equilibrium of the model}

A definition of equilibrium in this economy is standard, with 20 aggregate variables $\left(c_{t}, R_{t}, \Pi_{t}, d_{t}^{F}, d_{t}^{R F}, w_{t}, l_{t}^{d}, l_{t}^{s}, y_{t}^{d}, y_{t}^{S}, y_{t}^{d H}, y_{t}^{H}, f_{t}, w_{t}^{*}, N_{t}^{H}, v_{t}^{w}, k_{t}, q_{t}, r_{t}, i_{t}\right), 17^{*} \mathrm{~N}$ group s variables $\left(e_{t}^{s}, d_{t}^{F s}, d_{t}^{v F s}, d_{t}^{R F s}, l_{t}^{d s}, g_{t}^{s 1}, g_{t}^{s 2}, \widetilde{p}_{t}^{s}, \Pi_{t}^{s *}, N_{t}^{s}, v_{t}^{p s}, k_{t}^{s}, m c_{t}^{P s}, m c_{t}^{s}\right.$, $\left.a_{t}^{s}\left(a_{t}^{L s}, a_{t}^{S s}\right), \widetilde{a}_{t}^{s}, \bar{a}_{t}^{s}\right), 7$ entrants variables $\left(l_{t}^{d 0}, y_{t}^{d 0}, y_{t}^{0}, N_{t}^{0}, m c_{t}^{0}, e_{t}^{0}, k_{t}^{0}\right), 6$ aggregate shocks $\left(d_{t}, A_{t}, \mu_{t}, \varphi_{t}, f_{t}^{0}, m_{t}\right)$ and $\mathrm{N}$ group specific shocks $\left(A_{t}^{s}\right)$.

$$
\begin{aligned}
& \text { Euler eq. (bonds): } d_{t} c_{t}^{-\sigma}=\beta \mathbb{E}_{t}\left[d_{t+1} c_{t+1}^{-\sigma} \frac{R_{t}}{\Pi_{t+1}}\right] \\
& d_{t} c_{t}^{-\sigma} e_{t}^{s}=\beta\left(1-\delta^{F s}\right) \mathbb{E}_{t} d_{t+1} c_{t+1}^{-\sigma} * \\
& \begin{array}{c}
\text { Euler eq. } \\
(\mathrm{sh} \mathrm{s})
\end{array} \quad\left[\quad\left[\begin{array}{c}
d_{t+1}^{v F s+1} \int_{a_{t s}^{L s}}^{a^{\max }}\left(a_{i}\right)^{\gamma(\varepsilon-1)} d i \\
-\left(F_{t+1}^{s+1}+f_{t+1}^{L s+1}\right) \int_{a_{t+1}^{L s}}^{a^{\max }} d i+e_{t+1}^{s+1} \int_{a_{t+1}^{L s}}^{a^{\max }} d i
\end{array}\right)\right. \\
& \text { for } \mathrm{s}=1, \ldots, \mathrm{N} *+\left(d_{t+1}^{v F s} \int_{a_{t+1}^{S s}}^{a_{t+1}^{L s}}\left(a_{i}\right)^{\gamma(\varepsilon-1)} d i-F_{t+1}^{s} \int_{a_{t+1}^{S s}}^{a_{t+1}^{L s}} d i+e_{t+1}^{s} \int_{a_{t+1}^{S s}}^{a_{t s}^{L s}} d i\right) \\
& +\left(\begin{array}{c}
d_{t+1}^{v F s-1} \int_{a^{\min }}^{a_{t+1}^{S s}}\left(a_{i}\right)^{\gamma(\varepsilon-1)} d i \\
-\left(F_{t+1}^{s-1}+f_{t+1}^{S s-1}\right) \int_{a^{\min }}^{a_{t+1}^{S s}} d i+e_{t+1}^{s-1} \int_{a^{\min }}^{a_{t+1}^{S s}} d i
\end{array}\right) \\
& \text { Euler eq (capital): } q_{t}=\beta \mathbb{E}_{t} \frac{d_{t+1} c_{t+1}^{-\sigma}}{d_{t} c_{t}^{-\sigma}}\left\{q_{t+1}(1-\delta)+r_{t+1}\right\} \\
& \text { Tobin's q: } 1=q_{t} \mu_{t}\left(1-S\left[\frac{i_{t}}{i_{t-1}}\right]-S^{\prime}\left[\frac{i_{t}}{i_{t-1}}\right] \frac{i_{t}}{i_{t-1}}\right) \\
& +\beta \mathbb{E}_{t} q_{t+1} \frac{d_{t+1} c_{t+1}^{-\sigma}}{d_{t} c_{t}^{-\sigma}} \mu_{t+1} S^{\prime}\left[\frac{i_{t+1}}{i_{t}}\right]\left(\frac{i_{t+1}}{i_{t}}\right)^{2} \\
& f_{t}=\frac{\eta-1}{\eta}\left(w_{t}^{*}\right)^{1-\eta} d_{t} c_{t}^{-\sigma} w_{t}^{\eta} l_{t}^{d}+\beta \theta_{w} \mathbb{E}_{t}\left(\frac{\Pi^{1-\chi_{w}} \Pi_{t}^{\chi_{w}}}{\Pi_{t+1}}\right)^{1-\eta}\left(\frac{w_{t+1}^{*}}{w_{t}^{*}}\right)^{\eta-1} f_{t+1} \\
& f_{t}=d_{t} \varphi_{t} \psi\left(\frac{w_{t}^{*}}{w_{t}}\right)^{-\eta(1+\vartheta)}\left(l_{t}^{d}\right)^{1+\vartheta}+\beta \theta_{w} \mathbb{E}_{t}\left(\frac{\Pi^{1-\chi_{w}} \Pi_{t}^{\chi_{w}}}{\Pi_{t+1}}\right)^{-\eta(1+\vartheta)}\left(\frac{w_{t+1}^{*}}{w_{t}^{*}}\right)^{\eta(1+\vartheta)} f_{t+1}
\end{aligned}
$$


pricing (firms of size s, for $s=1, \ldots, N$ )

$$
\begin{gathered}
g_{t}^{s 1}=d_{t} c_{t}^{-\sigma} \frac{\varepsilon}{\varepsilon-1} \frac{m c_{t}^{P s}}{\bar{a}_{t}^{s}} y_{t}^{d H}+\beta \theta_{p}^{s} \mathbb{E}_{t}\left(\frac{\Pi^{1-\chi_{s}} \Pi_{t}^{\chi_{s}}}{\Pi_{t+1}}\right)^{-\varepsilon} g_{t+1}^{s 1} \\
g_{t}^{2 s}=d_{t} c_{t}^{-\sigma} y_{t}^{d H}+\beta \theta_{p}^{s} \mathbb{E}_{t}\left(\frac{\Pi^{1-\chi_{s}} \Pi_{t}^{\chi_{s}}}{\Pi_{t+1}}\right)^{(1-\varepsilon)} g_{t+1}^{s 2} \\
\Pi_{t}^{s *}=\frac{\varepsilon}{\varepsilon-1}\left[\frac{N-\xi_{c}\left(\Pi_{t}^{s *}\right)^{1-\varepsilon}}{N-\xi_{c} \frac{\varepsilon}{\varepsilon-1}\left(\Pi_{t}^{s *}\right)^{1-\varepsilon}}\right] \frac{g_{t}^{1 s}}{g_{t}^{2 s}}
\end{gathered}
$$

price dispersion (firms of size $\mathrm{s}$, for $s=1, \ldots, N$ ):

$\left(v_{t}^{p s}\right)^{-\varepsilon}=\left(1-\theta_{p}^{s}\right)\left(\Pi_{t}^{s *}\right)^{-\varepsilon}+\theta_{p}^{s}\left(\frac{\Pi^{1-\chi_{s}} \Pi_{t-1}^{\chi_{s}}}{\Pi_{t}}\right)^{-\varepsilon}\left(v_{t-1}^{p s}\right)^{-\varepsilon}$

heterogeneity effect (firms of size s, for $s=1, \ldots, N$ ):

$$
\begin{gathered}
N=\sum_{s=1}^{N}\left(\widetilde{p}_{t}^{s}\right)^{1-\varepsilon} \\
\Pi_{t}^{s *}=\left[\frac{\left(\widetilde{p}_{t}^{s}\right)^{1-\varepsilon}}{1-\theta_{p}^{s}}-\left(\frac{\Pi^{1-\chi_{s}} \Pi_{t-1}^{\chi_{s}}}{\Pi_{t}}\right)^{1-\varepsilon} \frac{\theta_{p}^{s}}{1-\theta_{p}^{s}}\left(\widetilde{p}_{t-1}^{s}\right)^{1-\varepsilon}\right]^{\frac{1}{1-\varepsilon}}
\end{gathered}
$$

aggregate wage

$$
w_{t}^{1-\eta}=\theta_{w}\left(\frac{\Pi^{1-\chi_{w}} \Pi_{t-1}^{\chi_{w}}}{\Pi_{t}}\right)^{1-\eta} w_{t-1}^{1-\eta}+\left(1-\theta_{w}\right) w_{t}^{* 1-\eta}
$$

wage dispersion:

$$
v_{t}^{w}=\left(1-\theta_{w}\right)\left(\frac{w_{t}^{*}}{w_{t-1}^{*}}\right)^{-\eta}+\theta_{w}\left(\frac{w_{t-1}}{w_{t}} \frac{\Pi^{1-\chi_{w}} \Pi_{t-1}^{\chi_{w}}}{\Pi_{t}}\right)^{-\eta} v_{t-1}^{w}
$$

number of firms (firms of size s, for $s=1, \ldots, N$ ):

$$
\begin{gathered}
N_{t}^{H}=\sum_{s=1}^{N} N_{t}^{s} \\
N_{t}^{s}=\left[\begin{array}{c}
\left(\int_{a_{t}^{L s-1}}^{a_{\max }^{L s}} d i\right)\left(1-\delta^{F s-1}\right) N_{t-1}^{s-1}+\left(\int_{a_{t}^{S s}}^{a^{L s}} d i\right)\left(1-\delta^{F s}\right) N_{t-1}^{s} \\
+\left(\int_{a^{\min }}^{a_{S s+1}} d i\right)\left(1-\delta^{F s+1}\right) N_{t-1}^{s+1}
\end{array}\right] \\
\text { free entry: } e_{t}^{0}=f_{t}^{0} m c_{t}^{0}
\end{gathered}
$$


Equity prices for entrants:

$$
e_{t}^{0}=\beta\left(1-\delta^{F 0}\right) \mathbb{E}_{t}\left\{\frac{d_{t+1} c_{t+1}^{-\sigma}}{d_{t} c_{t}^{-\sigma}}\left(d_{t+1}^{v F 1} \int_{a^{\min }}^{a^{\max }}\left(a_{i}\right)^{\gamma(\varepsilon-1)} d i+\left(e_{t+1}^{1}-F_{t+1}^{1}-f_{t+1}^{L 1}\right)\right)\right\}
$$

Threshold to upgrade size:

$$
\begin{aligned}
a_{t}^{L s}= & {\left[\frac{\left[\left(F_{t}^{s+1}+f_{t}^{L s+1}\right)-F_{t}^{s}\right]-\left(e_{t}^{s+1}-e_{t}^{s}\right)}{\frac{d_{t}^{v F s+1}}{\left(u c_{t}^{s+1}\right)^{\varepsilon-1}}-d_{t}^{v F s}}\right]^{\frac{1}{\gamma(\varepsilon-1)}} \text { for } s=1, \ldots, N-1 } \\
& a_{t}^{L N}=1 ; a_{t}^{L 0}=0 \text { all entrants grow endogenously }
\end{aligned}
$$

Threshold to downsize

$$
\begin{gathered}
a_{t}^{L s}=\left[\frac{\left[\left(F_{t}^{s+1}+f_{t}^{L s+1}\right)-F_{t}^{s}\right]-\left(e_{t}^{s+1}-e_{t}^{s}\right)}{\left.\frac{d_{t}^{v F s+1}}{\left(u c_{t}^{s+1}\right)^{\varepsilon-1}-d_{t}^{v F s}}\right]^{\frac{1}{\gamma(\varepsilon-1)}} \text { for } s=2, \ldots, N-1}\right. \\
a_{t}^{S 1}=\left[\frac{F_{t}^{1}-e_{t}^{1}}{d_{t}^{v F 1}}\right]^{\frac{1}{\gamma(\varepsilon-1)}} \\
a_{t}^{S 0}=0 \text { entrants do not die endogenously }
\end{gathered}
$$

dispersion of productivity (firms of size s, for $s=1, \ldots, N$ ):

$$
\begin{aligned}
& \left(\bar{a}_{t}^{s}\right)^{\varepsilon-1}=\frac{1}{N_{t}^{s}}\left[\begin{array}{c}
\left(1-\delta^{F s+1}\right) N_{t-1}^{s+1}\left(u c_{t}^{s+1}\right)^{(\varepsilon-1)} \int_{a_{t}^{\min }}^{a_{t}^{S s+1}}\left(a^{i}\right)^{\gamma(\varepsilon-1)} d i \\
+\left(1-\delta^{F s}\right) N_{t-1}^{s} \int_{a_{t}^{S s}\left(a^{i}\right)^{\gamma(\varepsilon-1)} d i}^{a^{L s}} d i \\
+\left(1-\delta^{F s-1}\right) N_{t-1}^{s-1} \frac{\int_{a_{t}^{L s-1}\left(a^{i}\right)^{\gamma(\varepsilon-1)}}^{a^{\max }} d i}{\left(u c_{t}^{s}\right)^{(\varepsilon-1)}}
\end{array}\right] \\
& \widetilde{a}_{t}^{s}=\frac{\left(\bar{a}_{t}^{s}\right)^{-\varepsilon}}{N_{t}^{s}}\left[\begin{array}{c}
\left(1-\delta^{F s+1}\right) N_{t-1}^{s+1}\left(u c_{t}^{s+1}\right)^{\varepsilon} \int_{a^{\min }}^{a_{S s+1}^{S}}\left(a_{t}^{i}\right)^{\gamma \varepsilon} d i \\
+\left(1-\delta^{F s}\right) N_{t-1}^{s} \int_{a_{t}^{S s}}^{a_{t}^{L s}\left(a_{t}^{i}\right)^{\gamma \varepsilon} d i} \\
+\left(1-\delta^{F s-1}\right) N_{t-1}^{s-1} \frac{\int_{a_{t}^{L}}^{a^{\max }}\left(a_{t}^{i}\right)^{\gamma \varepsilon} d i}{\left(u c_{t}^{s}\right)^{\varepsilon}}
\end{array}\right]
\end{aligned}
$$

profits of intermediate producers:

$$
\begin{gathered}
\text { aggregate: } d_{t}^{F}=\sum_{s=1}^{N} \frac{N_{t}^{s}}{N_{t}^{H}} d_{t}^{F s} \\
\text { firms of size s, for } s=1, \ldots, N \\
d_{t}^{F s}=\frac{1}{\varepsilon-1} \frac{m c_{t}^{P s} y_{t}^{d H}\left(v_{t}^{p s}\right)^{-\varepsilon}}{\bar{a}_{t}^{s} N N_{t}^{s}}-F_{t}^{s}-\left(1-\delta^{F s-1}\right) \frac{N_{t-1}^{s-1}}{N_{t}^{s}} f_{t}^{L s} \int_{a_{t}^{L s-1}}^{a^{\max }} d i \\
-\left(1-\delta^{F s+1}\right) \frac{N_{t-1}^{s+1}}{N_{t}^{s}} f_{t}^{S s} \int_{a^{\min }}^{a_{s}^{S+1}} d i \\
\text { profits indep of } a^{i} \\
d_{t}^{v F s}=\frac{1}{\varepsilon-1} \frac{m c_{t}^{P s} y_{t}^{d H}\left(v_{t}^{p s}\right)^{-\varepsilon}}{\left(\bar{a}_{t}^{s}\right)^{\varepsilon} N N_{t}^{s}}
\end{gathered}
$$


profits of retailers:

$$
\begin{gathered}
\text { aggregate: } d_{t}^{R F}=\sum_{s=1}^{N} d_{t}^{R F s} \\
\text { firms of size s, for } s=1, \ldots, N \\
d_{t}^{R F s}=\left[\left(\widetilde{p}_{t}^{s}\right)^{1-\varepsilon}-\left(v_{t}^{p s}\right)^{-\varepsilon}\left(\frac{\varepsilon}{\varepsilon-1}\right) \frac{m c_{t}^{P s}}{\bar{a}_{t}^{s}}\right] \frac{y_{t}^{d H}}{N}
\end{gathered}
$$

real marginal costs:

intermediate producers of size s, for $s=1, \ldots, N$

$$
\begin{gathered}
m c_{t}^{P s}=\left(\frac{1}{1-\alpha_{s}}\right)^{1-\alpha_{s}}\left(\frac{1}{\alpha_{s}}\right)^{\alpha_{s}} \frac{w_{t}^{1-\alpha_{s}} r_{t}^{\alpha_{s}}}{A_{t}^{s}} \\
\text { entrants } \\
m c_{t}^{0}=\left(\frac{1}{1-\alpha_{0}}\right)^{1-\alpha_{0}}\left(\frac{1}{\alpha_{0}}\right)^{\alpha_{0}} \frac{w_{t}^{1-\alpha_{0}} r_{t}^{\alpha_{0}}}{A_{t}^{0}}
\end{gathered}
$$

retailers of size s, for $s=1, \ldots, N$

$$
m c_{t}^{s}=\frac{\varepsilon}{\varepsilon-1} \frac{m c_{t}^{P s}}{\bar{a}_{t}^{s}}
$$

capital-labour ratio:

$$
\begin{gathered}
\frac{k_{t}^{s}}{l_{t}^{d s}}=\frac{\alpha_{s}}{1-\alpha_{s}} \frac{w_{t}}{r_{t}} \text { for } s=1, \ldots, N \\
\frac{k_{t}^{0}}{l_{t}^{d 0}}=\frac{\alpha_{0}}{1-\alpha_{0}} \frac{w_{t}}{r_{t}}
\end{gathered}
$$

Capital accumulation:

$$
\begin{gathered}
k_{t-1}=\sum_{s=0}^{N} k_{t}^{s} \\
k_{t}-(1-\delta) k_{t-1}-\mu_{t}\left(1-S\left[\frac{i_{t}}{i_{t-1}}\right]\right) i_{t}=0 .
\end{gathered}
$$

Taylor rule: $\frac{R_{t}}{R}=\left(\frac{R_{t-1}}{R}\right)^{\gamma_{R}}\left(\left(\frac{\Pi_{t}}{\Pi}\right)^{\gamma_{\Pi}}\left(\frac{y_{t}^{d H}}{y^{d H}}\right)^{\gamma_{y}}\right)^{1-\gamma_{R}} \exp \left(m_{t}\right)$

Established firms market:

$$
\begin{gathered}
y_{t}^{H}=\sum_{s=1}^{N} A_{t}^{s}\left(\frac{k_{t-1}^{s}}{l_{t}^{d s}}\right)^{\alpha_{s}} l_{t}^{d s} \bar{a}_{t}^{s} \widetilde{a}_{t}^{s} \\
l_{t}^{d s}=\frac{y_{t}^{d H}\left(v_{t}^{p s}\right)^{-\varepsilon}}{\bar{a}_{t}^{s} A_{t}^{s} N}\left(\frac{k_{t-1}^{s}}{l_{t}^{d s}}\right)^{-\alpha_{s}} \text { for } s=1, \ldots, N
\end{gathered}
$$




$$
\begin{gathered}
y_{t}^{d H}=c_{t}+i_{t}+\sum_{s=1}^{N} F_{t}^{s} N_{t}^{s}+\sum_{s=1}^{N}\left(\begin{array}{c}
\left(1-\delta^{F s-1}\right) N_{t-1}^{s-1} f_{t}^{L s} \int_{a_{t}^{L s-1}}^{a_{\max }^{L s}} d i \\
+\left(1-\delta^{F s+1}\right) N_{t-1}^{s+1} f_{t}^{S s} \int_{a^{\min }}^{a_{S s+1}^{S+1}} d i
\end{array}\right) \\
y_{t}^{d H}=\frac{y_{t}^{H}}{\sum_{s=1}^{N}\left(v_{t}^{p s}\right)^{-\varepsilon} \widetilde{a}_{t}^{s}}
\end{gathered}
$$

Entrants market:

$$
\begin{gathered}
y_{t}^{0}=A_{t}^{0}\left(\frac{k_{t}^{0}}{l_{t}^{d 0}}\right)^{\alpha_{0}} l_{t}^{d 0} \\
y_{t}^{d 0}=N_{t}^{0} e_{t}^{0} \\
y_{t}^{d 0}=m c_{t}^{0} y_{t}^{0}
\end{gathered}
$$

Labour market:

$$
\begin{gathered}
l_{t}^{s}=l_{t}^{d} v_{t}^{w} \\
l_{t}^{d}=\sum_{s=1}^{N} l_{t}^{d s}+l_{t}^{d 0}=\sum_{s=0}^{N} l_{t}^{d s}
\end{gathered}
$$

Aggregate demand \& supply:

$$
\begin{gathered}
y_{t}^{S}=\frac{y_{t}^{H}}{\sum_{s=1}^{N}\left(v_{t}^{p s}\right)^{-\varepsilon} \widetilde{a}_{t}^{s}}+m c_{t}^{0} y_{t}^{0} \\
y_{t}^{d}=y_{t}^{d H}+y_{t}^{d 0}
\end{gathered}
$$

\section{Appendix III: Rotemberg pricing}

Alternatively to the Calvo price-setting mechanism, in the literature it is often assumed the pricing mechanism suggested by Rotemberg (1982). According to this mechanism, in the second stage, each of the retailers to set the price, $p_{z t}^{s}$, that maximizes discounted real profits, have to pay a cost $p a c_{t}^{s}=\frac{\phi_{p}}{2}\left(\frac{p_{z t}^{R s}}{\Pi_{t-1}^{\chi_{s}} \Pi^{\left(1-\chi_{s}\right)} p_{z t-1}^{R s}}-1\right)^{2} p_{z t}^{R s} y_{z t}^{R s}$. In addition, we introduce indexation as in Ireland (2007), according to which all retailers index their prices to either past inflation or steady state inflation, which is controlled by the parameter $\chi_{s} \in[0,1]$, where $\chi_{s}=0$ represents indexation to steady state inflation only and $\chi_{s}=1$ corresponds to total indexation to past inflation. Optimizing retailers $z$ in class $s$ solve the following maximization problem

$$
\begin{gathered}
\max _{p_{z t}^{R s}} \mathbb{E}_{t} \sum_{\tau=0}^{\infty} \beta^{\tau} \frac{\lambda_{t+\tau}}{\lambda_{t}}\left\{\begin{array}{c}
\left(\frac{p_{z t+\tau}^{R s}}{p_{t+\tau} s}-m c_{t+\tau}^{R s}\right) y_{z t+\tau}^{R s} \\
-\frac{\phi_{p}}{2}\left(\frac{p_{z t+\tau}^{R s}}{\Pi_{t+\tau-1}^{\chi_{s}} \Pi^{\left(1-\chi_{s}\right.} p_{z t+\tau-1}^{R s}}-1\right)^{2} \frac{p_{z t+\tau}^{R s}}{p_{t+\tau}} y_{z t+\tau}^{R s}
\end{array}\right\}, \\
\text { s.t.: } \quad y_{z t+\tau}^{R s}=\left(N N^{R}\right)^{-1}\left(\frac{p_{z t+\tau}^{R s}}{p_{t+\tau}}\right)^{-\varepsilon} y_{t+\tau}^{H}, \quad \text { for } s=1, \ldots, N \\
p_{t}=\left[\left(N N^{R}\right)^{-1} \sum_{s=1}^{N} \sum_{z=1}^{N_{s}^{R s}}\left(p_{z t}^{s}\right)^{1-\varepsilon}\right]^{\frac{1}{1-\varepsilon}},
\end{gathered}
$$


where the discount factor takes into account the marginal value of a dollar to the household, which is treated as exogenous by the firm. In a symmetric equilibrium, the optimal (relative) price that solves this problem $\left(\Pi_{t}^{s *}=\frac{p_{t}^{s *}}{p_{t}}\right)$ is given by

$$
\begin{aligned}
\Pi_{t}^{s *} & =m c_{t}^{R s} \mu_{t}^{d s} \\
\mu_{t}^{d s} & =\frac{\eta_{p t}^{s *}}{\left\{1-\frac{\phi_{p}}{2}\left(g_{t}^{\pi^{s}}-1\right)^{2}\right\}\left(1+\eta_{p t}^{s *}\right)+\phi_{p} \Gamma_{t}^{R s}} \\
\Gamma_{t}^{R s} & =-\left(g_{t}^{\pi^{s}}-1\right) g_{t}^{\pi^{s}}+\beta \mathbb{E}_{t} \frac{\lambda_{t+1}}{\lambda_{t}}\left\{\left(g_{t+1}^{\pi^{s}}-1\right) g_{t+1}^{\pi^{s}} \frac{\Pi_{t+1}^{s *}}{\prod_{t}^{s *}} g_{t+1}^{y^{R s}}\right\} \\
g_{t}^{\pi^{s}} & =\frac{\Pi_{t}}{\Pi_{t-1}^{\chi_{s}} \Pi^{\left(1-\chi_{s}\right)}} \frac{\Pi_{t}^{s *}}{\Pi_{t-1}^{s *}} ; g_{t+1}^{y^{R s}}=\frac{y_{t+1}^{R s}}{y_{t}^{R s}}
\end{aligned}
$$

where $\eta_{p z t}^{s}$ is the price elasticity of demand that each retailer faces that can be expressed as a function of the elasticity of the aggregate price to the intermediate retailer price:

$$
\eta_{p z t}^{s}=\frac{\partial y_{z t+\tau}^{s}}{\partial p_{z t}^{s}} \frac{p_{z t}^{s}}{y_{z t+\tau}^{s}}=-\varepsilon\left(1-\frac{\partial p_{t}}{\partial p_{z t}^{s}} \frac{p_{z t}^{s}}{p_{t}}\right)
$$

where

$$
\frac{\partial p_{t}}{\partial p_{z t}^{s}} \frac{p_{z t}^{s}}{p_{t}}=s_{t}^{s}=\frac{p_{z t}^{s} y_{z t}^{s}}{p_{t} y_{t+\tau}^{d H}} .
$$

This aggregate price elasticity, in turn, equals the (nominal) market share of intermediate retailers and reflects that each individual firm takes into account the incidence of its own pricing decisions on the aggregate price, because these affect its own market share. This term is known in the literature as the strategic competition effect (see Etro and Colciago, 2010). If this strategic component is zero, then the price elasticity is constant, while if positive, the intensity of the strategic component will depend on the retailer's market share, which in turn is a function of the two key variables of the model: the number of firms in the market and the retailer's own optimal relative price, along the following expression

$$
s_{t}^{s}=\left(N N^{R}\right)^{-1}\left(\frac{p_{z t}^{s}}{p_{t}}\right)^{1-\varepsilon},
$$

and hence $\eta_{p z t}^{s}$ can be expressed as

$$
\eta_{p z t}^{s}=-\varepsilon\left(1-\left(N N^{R}\right)^{-1}\left(\frac{p_{z t}^{s}}{p_{t}}\right)^{1-\varepsilon}\right),
$$

This expression is key to understand the mechanism proposed in this paper regarding the response of inflation to different shocks. If firms are homogeneous, the strategic interaction is second order since the steady state market shares (and the elasticity of demand) are constant and identical across firms. In fact, in this case $\eta_{p z}^{s}$ is equal to the inverse of the number of firms, because their steady state optimal 
relative price is $\frac{p_{z}^{s}}{p}=1$ times the elasticity of substitution (and close to $\varepsilon$ if $N N^{R}$ is large). When there is firm heterogeneity, the strategic interaction component varies across types of firms and thus becomes relevant at the time of setting prices, since in this case individual pricing decisions affect market shares and thus the elasticity of their demand schedule. In particular, in the case explained here, with two types of firms, small and less productive firms face a higher steady state relative price $\frac{p_{z}^{s}}{p}>1$ and a smaller market share, both relative to larger firms and to the situation that would prevail in the case of homogenous firms, making the steady state elasticity of their demand greater. On the contrary, large and more productive firms set lower prices, $\frac{p_{z}^{s}}{p}<1$, and enjoy greater steady state market share, both relative to smaller firms and with respect to what would obtain in the case of homogenous firms, so that the elasticity of their demand is smaller, an aspect that has a significant effect on their price decisions. Therefore, small (large) firms tend to adjust their prices by a larger (smaller) amount after a shock both relative to large (small) firms and to the homogenous firm case of reference.

$$
\text { Homogeneous firms } \frac{p_{z}^{s}}{p}=1 \rightarrow\left|\eta_{p z}^{s}\right|=\varepsilon\left(1-\frac{1}{N N^{R}}\right) \approx \varepsilon
$$

Heterogeneous firms:

$$
\begin{aligned}
& \text { small } \frac{p_{z}^{s}}{p}>1 \rightarrow\left|\eta_{p z}^{\text {small }}\right|=\varepsilon\left(1-\frac{1}{N N^{R}\left(\frac{p_{z}^{s}}{p}>1\right)^{\varepsilon-1}}\right)>\eta_{p z}^{\text {homogenous }} \\
& \text { large } \frac{p_{z}^{s}}{p}<1 \rightarrow\left|\eta_{p z}^{\text {large }}\right|=\varepsilon\left(1-\frac{1}{N N^{R}\left(\frac{p_{z}^{s}}{p}<1\right)^{\varepsilon-1}}\right)<\eta_{p z}^{\text {homogenous }} .
\end{aligned}
$$

Expression (47) makes clear that firms set their optimal (relative) price $\left(\Pi_{t}^{s *}\right)$ as a markup $\left(\mu_{t}^{d s}\right)$ over marginal costs. $\mu_{t}^{d s}$ can be named "desired markup", since it is equal to the one prevalent under no price rigidities, and is decreasing in the elasticity of demand $\left(\eta_{p t}^{s}\right)$ and in the number of firms producing in the economy, while increasing in the firm's market share,

$$
\begin{aligned}
\mu_{t}^{d s} & =\frac{\varepsilon\left(1-\left(N N^{R}\right)^{-1}\left(\frac{p_{z t}^{s}}{p_{t}}\right)^{1-\varepsilon}\right)}{\left[\varepsilon\left(1-\left(N N^{R}\right)^{-1}\left(\frac{p_{z t}^{s}}{p_{t}}\right)^{1-\varepsilon}\right)-1\right]\left\{1-\frac{\phi_{p}}{2}\left(g_{t}^{\pi^{s}}-1\right)^{2}\right\}+\phi_{p} \Gamma_{t}^{R s}} \\
& =\frac{\varepsilon\left(1-s_{t}^{s}\right)}{\left[\varepsilon\left(1-s_{t}^{s}\right)-1\right]\left\{1-\frac{\phi_{p}}{2}\left(g_{t}^{\pi^{s}}-1\right)^{2}\right\}+\phi_{p} \Gamma_{t}^{R s}} .
\end{aligned}
$$

Notice that the desired markup is endogenous in the model since it depends on the price set by firms, $\Pi_{t}^{s *}$, and also on the TFP class the firm has optimally chosen, $s$. When there is no heterogeneity effect, $\frac{\partial p_{t}}{\partial p_{z t}^{s}} \frac{p_{z t}^{s}}{p_{t}}=0$, the desired markup is constant and exogenous to the firm, as in the standard case $\left(\mu^{d}=\frac{\varepsilon}{\varepsilon-1}\right)$. 
Finally, in a symmetric equilibrium under Rottemberg pricing all firms of the same type set the same price every period, but there are differences across types. Consequently, the aggregate price index for retailers of each size group is equal to the optimal price of that group, or in relative terms to the aggregate price

$$
\widetilde{p}_{t}^{s}=\Pi_{t}^{s *}
$$

where $\widetilde{p}_{t}^{s}=\frac{p_{t}^{s}}{p_{t}}$, and the aggregate price index must satisfy the condition

$$
1=\sum_{s=1}^{N} \frac{\left(\Pi_{t}^{s *}\right)^{-(\varepsilon-1)}}{N}
$$

\subsection{The Phillips curve under Rotemberg pricing}

Key to understanding the differences of our setup with respect to the standard New Keynesian one (with homogeneous firms and Dixit-Stiglitz monopolistic competition) is the specification of the Phillips curve in both settings. In the model of this paper, the dynamics of inflation are driven by price stickiness that occurs at the intermediate retailers (IR) level. Log linearizing the pricing block of the model, i.e. equations in (47) and (48), and after some algebra, the dynamics of inflation of firms in the technology class $s$ can be represented as,

$$
\left(\widehat{\Pi}_{t}^{s}-\chi_{s} \widehat{\Pi}_{t-1}^{s}\right)=\frac{\left|\eta_{p}^{R s}\right|-1}{\phi_{p}} \widehat{m c}_{t}^{R s \prime}+\beta \mathbb{E}_{t}\left[\widehat{\Pi}_{t+1}^{s}-\chi_{s} \widehat{\Pi}_{t}\right]+\frac{1}{\phi_{p}}\left|\widehat{\eta}_{p t}^{s *}\right|
$$

where $\widehat{m c}_{t}^{R s \prime}$ is the real marginal cost in terms of sector prices $\left(m c_{t}^{R s^{\prime}}=\frac{M C_{t}^{R s}}{p_{t}^{s}}\right)$. The most relevant new component in this representation of the Phillips curve, as compared to the one in the standard New Keynesian model, is the term in the demand elasticity of substitution $\left(\left|\eta_{p}^{s *}\right|\right)$. As a first approximation, its role is equivalent to the markup shocks that are very often exogenously introduced in the Phillips curve to generate cost push shocks to inflation in a way that removes the divine coincidence (Blanchard and Galí, 2007; International Monetary Fund, 2019a). However the crucial difference is that here this demand elasticity enters endogenously in the equation and it responds itself to changes in inflation. In fact, making use of the equations (10), (5) and (11) we can show that,

$$
\begin{gathered}
\left|\widehat{\eta}_{p t}^{s *}\right|=\frac{s^{s *}}{1-s^{s *}} \widehat{s}_{t}^{s *}, \\
\widehat{s}_{t}^{s *}=-(\varepsilon-1) \widehat{\Pi}_{t}^{s *} .
\end{gathered}
$$

Expression above confirms that changes in the (absolute value of the) demand elasticity of substitution are positively related to changes in the market share. As expected, the market share diminishes when firms in the $s$ technological category 
rise their relative price. Combining all these elements, the mechanism linking heterogeneity and Bertrand competition is made clear. Positive shocks to the marginal cost in a given technological class $s$ increase the inflation rate through the usual Rotemberg channel, but this ends up eroding market power of firms in that category, which leads firm to charge a lower markup on expected marginal costs, thus moderating the inflation rise. (A symmetric response occurs following negative shocks to marginal costs.)

These effects can be better viewed in a more compact form by plugging these expressions into the NKPC, so that the dynamics of inflation in the $s$ technological class can be expressed as,

$$
\begin{aligned}
\left(\widehat{\Pi}_{t}^{s}-\frac{\chi_{s}}{1+\xi_{N}^{s}} \widehat{\Pi}_{t-1}^{s}\right) & =\underbrace{\left(\frac{\beta}{1+\xi_{N}^{s}}\right)}_{\text {Heterogeneity effect }} \beta \mathbb{E}_{t}\left(\widehat{\Pi}_{t+1}^{s}-\chi_{s} \widehat{\Pi}_{t}^{s}\right) \\
& +\overbrace{\left(\frac{1}{1+\xi_{N}^{s}}\right)}^{\mid \frac{\left|\eta_{p}^{R s}\right|-1}{\phi_{p}}\left(\widehat{m c}_{t}^{s \prime}-\widehat{\bar{a}}_{t}^{s}\right)+f\left(\Delta \widehat{p}_{t}^{s}\right),}
\end{aligned}
$$

where

$$
\begin{aligned}
\xi_{N}^{s} & =\frac{(\varepsilon-1) s^{s *}}{1-s^{s *}}>0 ;\left\{\frac{\partial \xi_{N}^{s}}{\partial \varepsilon}\right\}_{\bar{s}^{R s *}}>0, \frac{\partial \xi_{N}^{s}}{\partial s^{s *}}>0, \\
\widehat{\bar{a}}_{t}^{s} & =\rho_{N}^{s+1} \widehat{N}_{t-1}^{s+1}+\rho_{N}^{s} \widehat{N}_{t-1}^{s}+\rho_{N}^{s-1} \widehat{N}_{t-1}^{s-1}+\rho_{a}^{s} \widehat{a}_{t}^{s}+\rho_{a}^{s-1} \widehat{a}_{t}^{s-1} \\
f\left(\Delta \widehat{p}_{t}^{s}\right) & =\frac{1}{1-\xi^{s}}\left[\xi^{s}\left(\widehat{p}_{t}-\widehat{p}_{t-1}-\widehat{\rho}_{t-1}^{s}\right)+\beta \chi_{s}\left(\widehat{\rho}_{t}^{s}-\widehat{\rho}_{t-1}^{s}\right)-\chi_{s}\left(\widehat{\rho}_{t-1}^{s}-\widehat{\rho}_{t-2}^{s}\right)\right],
\end{aligned}
$$

and $\rho_{N}^{s}$ and $\rho_{a}^{s}$ are convolutions of structural parameters. The term $\widehat{\bar{a}}_{t}^{s}$ captures changes in the composition of average productivity shocks of firms of type $s$ as well as changes in the number of firms in this technology group due to upgrading and downgrading to and from adjacent classes. Changes in this term are small at the business cycle frequency and so is their impact on inflation rates. Also, due to heterogeneity in productivity across firms, a term representing the impact of the change in relative prices, $f\left(\Delta \widehat{p}_{t}^{s}\right)$, shows up, whose quantitative relevance on the dynamics of inflation is also second order.

According to (49), inflation dynamics in our model can be understood as determined, as in the standard New Keynesian case, solely by the dynamics of marginal costs and expected inflation, but now their coefficients are pre-multiplied by (a function) of the parameter $\xi_{N}^{s}$, which represents the heterogeneity effect. The value of $\xi_{N}^{s}$ depends entirely on the elasticity of substitution among varieties and on the steady state market share of each type of firms which in turn depends on the optimal relative price, $\Pi^{s *}$. In particular, the larger is the market share of firms of type $s$, the stronger the heterogeneity effect and the smaller the response of inflation to changes in the marginal cost. 
The intuition behind this result can be gained again by looking at how the impact of changes in the market share on the desired markup is increasing in the steady state market share itself. Firms with less efficient technologies will charge a price above the market average, i.e. a relative price above one $\left(\Pi^{s *}>1\right)$; because of this, their market share $\left(s_{t}^{s}=\left(N N^{R}\left(\Pi^{s *}\right)^{\varepsilon-1}\right)^{-1} \Rightarrow 0\right)$ will tend to zero thus making the impact of further changes in the market share on their desired markup negligible. More efficient firms charge a price below the market average $\left(\Pi^{s *}<1\right)$ and will achieve a significant market share as time goes by, implying that the impact of variations in their market share on the desired markup are significant.

Both firm heterogeneity and Bertrand competition are jointly required for the heterogeneity effect to be first order. If there is no strategic price competition, then $\frac{\partial p}{\partial p^{s *}} \frac{p^{s *}}{p}=0$, and the desired markup coincides with the standard case, $\mu^{d}=\frac{\varepsilon}{\varepsilon-1}$ and $\xi_{N}^{s}=0$; in this case the expression in (49) boils down to the standard NKPC. In other words, if there is no strategic pricing, the presence of firms with different technologies is basically irrelevant as far as the dynamics of aggregate inflation is concerned, since all intermediate retailers would perceive their desired markup as constant and irresponsive to market shares and pricing. On the other hand, even in the presence of strategic pricing, if firms are homogeneous (equally productive and hence with a relative price equal to 1 ) the market share of intermediate retailers would be constant and proportionally inverse to the number of firms; thus for sufficiently large $N N^{R}$, again $\eta_{p}^{s *}$ would get arbitrarily close to $-\varepsilon$, making $\xi_{N}^{s}$ very small with a negligible impact on inflation dynamics. ${ }^{19}$

Firm heterogeneity and strategic pricing together reduce the magnitude of the coefficients of the drivers of inflation that appear in the standard NKPC, dampening the response of the inflation rate to current and expected future marginal costs. This effect carries over to the aggregate inflation rate. Using equation (2), aggregate inflation can be expressed as the weighted average of the inflation rates of each firmsize, where the weights are the steady state market shares of intermediate retailers

$$
\begin{aligned}
& \left(s^{s *}=\frac{\left(\Pi^{s *}\right)^{1-\varepsilon}}{N N^{R}}\right) \text { so that } \widehat{\Pi}_{t}=\sum_{s=1}^{N} s^{s *} \widehat{\Pi}_{t}^{s} \text { and we can write the aggregate NKPC as } \\
& \left(\widehat{\Pi}_{t}-\sum_{s=1}^{N}\left(\Pi^{s *}\right)^{1-\varepsilon} \frac{\chi_{s}}{1+\xi_{N}^{s}} \widehat{\Pi}_{t-1}^{s}\right)=\left[\begin{array}{c}
\sum_{s=1}^{N} s^{s *}\left(\frac{\beta}{1+\xi_{N}^{s}}\right) \beta \mathbb{E}_{t}\left(\widehat{\Pi}_{t+1}^{s}-\chi_{s} \widehat{\Pi}_{t}^{s}\right) \\
+\sum_{s=1}^{N} s^{s *}\left(\frac{1}{1+\xi_{N}^{s}}\right) \frac{\left|\eta_{p}^{R s}\right|-1}{\phi_{p}}\left(\widehat{m c}_{t}^{s \prime}-\widehat{\bar{a}}_{t}^{s \prime}\right)
\end{array}\right] .
\end{aligned}
$$

Therefore, aggregate inflation dynamics are strongly influenced by the pricing behavior of large firms, which in turn react less to changes in their marginal costs. Hence, as market share polarization increases, the aggregate Phillips curve gets flatter.

\footnotetext{
${ }^{19}$ If the number of firms $N N^{R}$ is sufficiently small so that the entry and exit of firms changes significantly the market share of each of them, we would obtain a moderating effect on inflation qualitatively similar to the heterogeneity effect described here. This mechanism is present in the model developed by Etro and Rossi (2015).
} 


\section{References}

[1] Aghion, P., A. Bergeaud, T. Boppart, J. Klenow and L. Huiyu (2019). Theory of Falling Growth and Rising Rents, CEPR Discussion Paper 14094.

[2] Akcigit, U., and S. T. Ates (2019). Ten Facts on Declining Business Dynamism and Lessons from Endogenous Growth Theory, NBER Working Paper 25755.

[3] Amiti, M., O. Itskhoki and J. Konings (2019). "International Shocks, Variable Markups, and Domestic Prices", The Review of Economic Studies, 86(6).

[4] Andrés, J., and P. Burriel (2014). Inflation dynamics in a model with firm entry and (some) heterogeneity, Documentos de Trabajo, No. 1427, Banco de España.

[5] — (2018). "Inflation and optimal monetary policy in a model with firm heterogeneity and Bertrand competition", European Economic Review, No. 103, pp. $18-38$.

[6] Andrews, D., C. Criscuolo and P. Gal (2015). Frontier Firms, Technology Diffusion and Public Policy, OECD Productivity Working Papers, No. 2.

[7] — (2016). The Best versus the Rest: The Global Productivity Slowdown, Divergence across Firms and the Role of Public Policy, OECD Productivity Working Papers, No. 5.

[8] Autor, D., D. Dorn, L. Katz, C. Patterson and J. Van Reenen (2018). "Concentrating on the Fall of the Labor Share", American Economic Review Papers and Proceedings, 107(5), pp. 180-185.

[9] - (2020). "The Fall of the Labor Share and the Rise of Superstar Firms", Quarterly Journal of Economics, 135(2), pp. 645-709.

[10] Bajgar, M., G. Berlingieri, S. Calligaris, C. Criscuolo and J. Timmis (2019). Industry Concentration in Europe and North America, CEP Discussion Paper 1654, Centre for Economic Performance, LSE.

[11] Barkai, S. (2020). "Declining labor and capital shares", Journal of Finance, 75(5), pp. 2421-2463.

[12] Bartelsman, E., J. Haltiwanger and S. Scarpetta (2013). "Cross-Country Differences in Productivity: The Role of Allocation and Selection", American Economic Review, 103(1), pp. 305-334.

[13] Bergin, P., L. Feng and C. Lin (2018). "Firm Entry and Financial Shocks", The Economic Journal, 128(609), pp. 510-540. 
[14] Berlingieri, G., P. Blanchenay and C. Criscuolo (2017). The Great Divergence(s), CEPR Discussion Paper 1488.

[15] Bernard, A. B., S. J. Redding and P. K. Schott (2010). "Multi-product Firms and Product Switching", American Economic Review, Vol. 100, pp. 70-97.

[16] Bilbiie, F. O., F. Ghironi and M. J. Melitz (2012). "Endogenous Entry, Product Variety, and Business Cycles", Journal of Political Economy, 120(2), pp. 304345 .

[17] Blanchard, O. (2016). "The US Phillips Curve: Back to the 60s?", American Economic Review: Papers \& Proceedings, 106(5), pp. 31-34.

[18] Blanchard, O., and J. Galí (2007). "Real Wage Rigidities and the New Keynesian Model", Journal of Money, Credit and Banking, 39(1), pp. 35-65.

[19] Browning, M., L. P. Hansen and J. J. Heckman (1999). "Micro data and general equilibrium models", in J. B. Taylor and M. Woodford (eds.), Handbook of Macroeconomics, Vol. 1, Part A, pp. 543-633.

[20] Clarida, R., J. Galí and M. Gertler (2000). "Monetary Policy Rules and Macroeconomic Stability: Evidence and Some Theory", The Quarterly Journal of Economics, 115(1), pp. 147-180.

[21] Cohen, P. (2017). How Amazon overpowers the Fed, Forbes, August 25.

[22] Covarrubias, M., G. Gutiérrez and T. Philippon (2019). From Good to Bad Concentration? U.S. Industries Over the Past 30 Years, NBER Working Paper 25983.

[23] De Loecker, J., and J. Eeckhout (2018). Global Market Power, NBER Working Paper 24768.

[24] De Loecker, J., J. Eeckhout and G. Unger (2020). "The Rise of Market Power and the Macroeconomic Implications", Quarterly Journal of Economics, 135(2), pp. 561-644.

[25] Decker, R., J. Haltiwanger, R. Jarmin and J. Miranda (2014). The secular decline in business dynamism in the US, University of Maryland, mimeo.

[26] — (2016). Declining Business Dynamism: What We Know and the Way Forward", American Economic Review: Papers $\&$ Proceedings, 106(5), pp. 203-207.

[27] Del Negro, M., M. Lenza, G. E. Primiceri and A. Tambalotti (2020). What's up with the Phillips Curve?, NBER Working Paper 27003. 
[28] Eggertsson, G., J. Robbins and E. Wold (2018). Kaldor and Piketty's Facts: The Rise of Monopoly Power in the United States, NBER Working Paper 24287.

[29] Erceg, C. J., D. W. Henderson and A. T. Levin (2000). "Optimal monetary policy with staggered wage and price contracts", Journal of Monetary Economics, 46(2), pp. 281-313, October.

[30] Etro, F., and A. Colciago (2010). "Endogenous Market Structures and the Business Cycle", The Economic Journal, 120(549), pp. 1201-1233.

[31] Etro, F., and L. Rossi (2015). "New-Keynesian Phillips curve with Bertrand competition and endogenous entry", Journal of Economic Dynamics $\&$ Control, 51(3), pp. 318-340.

[32] Fernández, C., and P. López (2014). Explaining small firms' TFP gap: An analysis with Italian, Spanish and French firm-level data, Banco de España, mimeo.

[33] Fernández-Villaverde, J. (2010). "The econometrics of DSGE models", SERIEs, 1(1), pp. 3-49.

[34] Ghironi, F. (2017). Macro needs Micro, CEPR Discussion Paper 12299.

[35] Gros, D. (2017). "How Amazon fuels deflation", Tech and Innovation, August 30.

[36] Grullon, G., Y. Larkin and R. Michaely (2019). "Are U.S. Industries Becoming More Concentrated?", Review of Finance, 23(4), pp. 697-743.

[37] Gutiérrez, G., C. Jones and T. Philippon (2019). Entry Costs and the Macroeconomy, NBER Working Paper 25609.

[38] Hooper, P., F. S. Mishkin and A. Sufi (2019). Prospects for Inflation in a High Pressure Economy: Is the Phillips Curve Dead or is It Just Hibernating?, NBER Working Paper 25792.

[39] International Monetary Fund (2013). "The Dog that Didn't Bark: Has Inflation Been Muzzled or Was it Just Sleeping?", World Economic Outlook: Hopes, Realities, Risks, Chapter 3, pp. 79-96, April.

[40] - (2019a). "The Rise of Corporate Market Power and its Macroeconomic Effects", World Economic Outlook: Growth Slowdown, Precarious Recovery, Chapter 2, pp. 55-76, April.

[41] — (2019b). "Wage Growth and Inflation in Europe: A Puzzle?", Regional Economic Outlook. Europe: Facing Spillovers from Trade and Manufacturing, Chapter 2, pp. 13-27, November. 
[42] Ireland, P. (2007). "Changes in the Federal Reserve's Inflation Target: Causes and Consequences", Journal of Money, Credit and Banking, 39(8), pp. 18511882.

[43] Kehrig, M., and N. Vincent (2018). The Micro-Level Anatomy of the Labor Share Decline, NBER Working Paper 25275.

[44] Krueger, A. (2018). "Reflections on Dwindling Worker Bargaining Power and Monetary Policy", Jackson Hole Economic Symposium, Monetary Policy in a Changing Economy.

[45] Powell, J. (2018). "Introductory Remarks", Jackson Hole Symposium, Monetary Policy in a Changing Economy.

[46] Rotemberg, J. (1982). "Sticky Prices in the United States", Journal of Political Economy, 90(6), pp. 1187-1211.

[47] Schivardi, F., and R. Torrini (2004). "Threshold effects and firm size. The case of firing costs", Meeting Papers, No. 445, Society for Economic Dynamics.

[48] Siebale, J., J. Suedekum and N. Woessner (2020). Robots and the Rise of European Superstar Firms, CEPR Discussion Paper 15080.

[49] Stansbury, A., and L. Summers (2020). The Declining Worker Power Hypothesis: An Explanation for the Recent Evolution of the American Economy, NBER Working Paper 27193.

[50] Stock, J. H., and M. W. Watson (2003). "Has the Business Cycle Changed and Why?", in M. Gertler and K.S. Rogoff (eds.), NBER Macroeconomics Annual 2002, Vol. 17, pp. 159-230.

[51] — (2019). Slack and Cyclically Sensitive Inflation, NBER Working Paper 25987.

[52] Syverson, C. (2004). "Product Substitutability and Productivity Dispersion", Review of Economics and Statistics, 86(2), pp. 534-550.

[53] — (2011). "What Determines Productivity?", Journal of Economic Literature, 49(2), pp. 326-365.

[54] - (2018). "Changing Market Structure and Implications for Monetary Policy", Remarks at the Jackson Hole Economic Policy Symposium.

[55] — (2019). "Macroeconomics and Market Power: Context, Implications, and Open Questions", Journal of Economic Perspectives, 33(3), pp. 23-43. 
[56] Van Reenen, J. (2018). Increasing Differences Between Firms: Market Power and the Macro-Economy, CEP Discussion Paper 1576, Centre for Economic Performance, LSE.

[57] Wang, O., and I. Werning (2020). Dynamic Oligopoly and Price Stickiness, NBER Working Paper 27536.

[58] World Bank (2020). World Development Report 2020: Trading for Development in the Age of Global Value Chains, Washington DC. 


\section{BANCO DE ESPAÑA PUBLICATIONS}

\section{WORKING PAPERS}

1940 MYROSLAV PIDKUYKO: Heterogeneous spillovers of housing credit policy.

1941 LAURA ÁLVAREZ ROMÁN and MIGUEL GARCÍA-POSADA GÓMEZ: Modelling regional housing prices in Spain.

1942 STÉPHANE DÉES and ALESSANDRO GALESI: The Global Financial Cycle and US monetary policy

in an interconnected world.

1943 ANDRÉS EROSA and BEATRIZ GONZÁLEZ: Taxation and the life cycle of firms.

1944 MARIO ALLOZA, JESÚS GONZALO and CARLOS SANZ: Dynamic effects of persistent shocks.

1945 PABLO DE ANDRÉS, RICARDO GIMENO and RUTH MATEOS DE CABO: The gender gap in bank credit access.

1946 IRMA ALONSO and LUIS MOLINA: The SHERLOC: an EWS-based index of vulnerability for emerging economies.

1947 GERGELY GANICS, BARBARA ROSSI and TATEVIK SEKHPOSYAN: From Fixed-event to Fixed-horizon Density Forecasts: Obtaining Measures of Multi-horizon Uncertainty from Survey Density Forecasts.

1948 GERGELY GANICS and FLORENS ODENDAHL: Bayesian VAR Forecasts, Survey Information and Structural Change in the Euro Area.

2001 JAVIER ANDRÉS, PABLO BURRIEL and WENYI SHEN: Debt sustainability and fiscal space in a heterogeneous Monetary Union: normal times vs the zero lower bound.

2002 JUAN S. MORA-SANGUINETTI and RICARDO PÉREZ-VALLS: ¿Cómo afecta la complejidad de la regulación a la demografía empresarial? Evidencia para España

2003 ALEJANDRO BUESA, FRANCISCO JAVIER POBLACIÓN GARCÍA and JAVIER TARANCÓN: Measuring the procyclicality of impairment accounting regimes: a comparison between IFRS 9 and US GAAP.

2004 HENRIQUE S. BASSO and JUAN F. JIMENO: From secular stagnation to robocalypse? Implications of demographic and technological changes.

2005 LEONARDO GAMBACORTA, SERGIO MAYORDOMO and JOSÉ MARÍA SERENA: Dollar borrowing, firm-characteristics, and FX-hedged funding opportunities.

2006 IRMA ALONSO ÁLVAREZ, VIRGINIA DI NINO and FABRIZIO VENDITTI: Strategic interactions and price dynamics in the global oil market.

2007 JORGE E. GALÁN: The benefits are at the tail: uncovering the impact of macroprudential policy on growth-at-risk.

2008 SVEN BLANK, MATHIAS HOFFMANN and MORITZ A. ROTH: Foreign direct investment and the equity home bias puzzle.

2009 AYMAN EL DAHRAWY SÁNCHEZ-ALBORNOZ and JACOPO TIMINI: Trade agreements and Latin American trade (creation and diversion) and welfare.

2010 ALFREDO GARCÍA-HIERNAUX, MARÍA T. GONZÁLEZ-PÉREZ and DAVID E. GUERRERO: Eurozone prices: a tale of convergence and divergence.

2011 ÁNGEL IVÁN MORENO BERNAL and CARLOS GONZÁLEZ PEDRAZ: Sentiment analysis of the Spanish Financial Stability Report. (There is a Spanish version of this edition with the same number).

2012 MARIAM CAMARERO, MARÍA DOLORES GADEA-RIVAS, ANA GÓMEZ-LOSCOS and CECILIO TAMARIT: External imbalances and recoveries.

2013 JESÚS FERNÁNDEZ-VILLAVERDE, SAMUEL HURTADO and GALO NUÑO: Financial frictions and the wealth distribution.

2014 RODRIGO BARBONE GONZALEZ, DMITRY KHAMETSHIN, JOSÉ-LUIS PEYDRÓ and ANDREA POLO: Hedger of last resort: evidence from Brazilian FX interventions, local credit, and global financial cycles.

2015 DANILO LEIVA-LEON, GABRIEL PEREZ-QUIROS and EYNO ROTS: Real-time weakness of the global economy: a first assessment of the coronavirus crisis.

2016 JAVIER ANDRÉS, ÓSCAR ARCE, JESÚS FERNÁNDEZ-VILLAVERDE and SAMUEL HURTADO: Deciphering the macroeconomic effects of internal devaluations in a monetary union.

2017 FERNANDO LÓPEZ-VICENTE, JACOPO TIMINI and NICOLA CORTINOVIS: Do trade agreements with labor provisions matter for emerging and developing economies' exports?

2018 EDDIE GERBA and DANILO LEIVA-LEON: Macro-financial interactions in a changing world.

2019 JAIME MARTÍNEZ-MARTÍN and ELENA RUSTICELLI: Keeping track of global trade in real time.

2020 VICTORIA IVASHINA, LUC LAEVEN and ENRIQUE MORAL-BENITO: Loan types and the bank lending channel.

2021 SERGIO MAYORDOMO, NICOLA PAVANINI and EMANUELE TARANTINO: The impact of alternative forms of bank consolidation on credit supply and financial stability.

2022 ALEX ARMAND, PEDRO CARNEIRO, FEDERICO TAGLIATI and YIMING XIA: Can subsidized employment tackle long-term unemployment? Experimental evidence from North Macedonia. 
2023 JACOPO TIMINI and FRANCESCA VIANI: A highway across the Atlantic? Trade and welfare effects of the EU-Mercosur agreement.

2024 CORINNA GHIRELLI, JAVIER J. PÉREZ and ALBERTO URTASUN: Economic policy uncertainty in Latin America: measurement using Spanish newspapers and economic spillovers.

2025 MAR DELGADO-TÉLLEZ, ESTHER GORDO, IVÁN KATARYNIUK and JAVIER J. PÉREZ: The decline in public investment: "social dominance" or too-rigid fiscal rules?

2026 ELVIRA PRADES-ILLANES and PATROCINIO TELLO-CASAS: Spanish regions in Global Value Chains: How important? How different?

2027 PABLO AGUILAR, CORINNA GHIRELLI, MATÍAS PACCE and ALBERTO URTASUN: Can news help measure economic sentiment? An application in COVID-19 times.

2028 EDUARDO GUTIÉRREZ, ENRIQUE MORAL-BENITO, DANIEL OTO-PERALÍAS and ROBERTO RAMOS: The spatial distribution of population in Spain: an anomaly in European perspective.

2029 PABLO BURRIEL, CRISTINA CHECHERITA-WESTPHAL, PASCAL JACQUINOT, MATTHIAS SCHÖN and NIKOLA STÄHLER: Economic consequences of high public debt: evidence from three large scale DSGE models.

2030 BEATRIZ GONZÁLEZ: Macroeconomics, Firm Dynamics and IPOs.

2031 BRINDUSA ANGHEL, NÚRIA RODRÍGUEZ-PLANAS and ANNA SANZ-DE-GALDEANO: Gender Equality and the Math Gender Gap.

2032 ANDRÉS ALONSO and JOSÉ MANUEL CARBÓ: Machine learning in credit risk: measuring the dilemma between prediction and supervisory cost.

2033 PILAR GARCÍA-PEREA, AITOR LACUESTA and PAU ROLDAN-BLANCO: Raising Markups to Survive: Small Spanish Firms during the Great Recession.

2034 MÁXIMO CAMACHO, MATÍAS PACCE and GABRIEL PÉREZ-QUIRÓS: Spillover Effects in International Business Cycles.

2035 ÁNGEL IVÁN MORENO and TERESA CAMINERO: Application of text mining to the analysis of climate-related disclosures.

2036 EFFROSYNI ADAMOPOULOU and ERNESTO VILLANUEVA: Wage determination and the bite of collective contracts in Italy and Spain: evidence from the metal working industry.

2037 MIKEL BEDAYO, GABRIEL JIMÉNEZ, JOSÉ-LUIS PEYDRÓ and RAQUEL VEGAS: Screening and Loan Origination Time: Lending Standards, Loan Defaults and Bank Failures.

2038 BRINDUSA ANGHEL, PILAR CUADRADO and FEDERICO TAGLIATI: Why cognitive test scores of Spanish adults are so low? The role of schooling and socioeconomic background

2039 CHRISTOPH ALBERT, ANDREA CAGGESE and BEATRIZ GONZÁLEZ: The Short- and Long-run Employment Impact of COVID-19 through the Effects of Real and Financial Shocks on New Firms.

2040 GABRIEL JIMÉNEZ, DAVID MARTíNEZ-MIERA and JOSÉ-LUIS PEYDRÓ: Who Truly Bears (Bank) Taxes? Evidence from Only Shifting Statutory Incidence.

2041 FELIX HOLUB, LAURA HOSPIDO and ULRICH J. WAGNER: Urban air pollution and sick leaves: evidence from social security data.

2042 NÉLIDA DÍAZ SOBRINO, CORINNA GHIRELLI, SAMUEL HURTADO, JAVIER J. PÉREZ and ALBERTO URTASUN: The narrative about the economy as a shadow forecast: an analysis using Banco de España quarterly reports.

2043 NEZIH GUNER, JAVIER LÓPEZ-SEGOVIA and ROBERTO RAMOS: Reforming the individual income tax in Spain.

2101 DARÍO SERRANO-PUENTE: Optimal progressivity of personal income tax: a general equilibrium evaluation for Spain.

2102 SANDRA GARCÍA-URIBE, HANNES MUELLER and CARLOS SANZ: Economic uncertainty and divisive politics: evidence from the Dos Españas

2103 IVÁN KATARYNIUK, VÍCTOR MORA-BAJÉN and JAVIER J. PÉREZ: EMU deepening and sovereign debt spreads: using political space to achieve policy space.

2104 DARÍO SERRANO-PUENTE: Are we moving towards an energy-efficient low-carbon economy? An input-output LMDI decomposition of $\mathrm{CO}_{2}$ emissions for Spain and the EU28.

2105 ANDRÉS ALONSO and JOSÉ MANUEL CARBÓ: Understanding the performance of machine learning models to predict credit default: a novel approach for supervisory evaluation.

2106 JAVIER ANDRÉS, ÓSCAR ARCE and PABLO BURRIEL: Market polarization and the Phillips curve. 